\title{
Cold and Hot Gelling of Alginate-graft-PNIPAM: a Schizophrenic Behavior Induced by Potassium Salts
}

Hui Guo $^{1,2}$, Mickael de Magalhaes Goncalves ${ }^{1,2}$, Guylaine Ducouret ${ }^{1,2}$ and Dominique Hourdet ${ }^{1,2}$

${ }^{1}$ Laboratoire Sciences et Ingénierie de la Matière Molle, CNRS, ESPCI Paris,

PSL Research University, 10 rue Vauquelin, F-75005 Paris, France.

${ }^{2}$ Laboratoire Sciences et Ingénierie de la Matière Molle, Université Pierre et Marie Curie,

Sorbonne-Universités, 10 rue Vauquelin, F-75005 Paris, France.

Email addresses:

hui.guo@espci.fr,

mickael-de-magalhaes@sfr.fr,

guylaine.ducouret@espci.fr,

dominique.hourdet@espci.fr 


\section{ABSTRACT}

Recently, alginates (ALG) characterized by high mannuronic content (M blocks) have been shown to undergo a reversible sol/gel transition during cooling in the presence of potassium salts. Cold gelling takes place at low temperatures, just below $0{ }^{\circ} \mathrm{C}$ for a $\mathrm{KCl}$ concentration of $0.3 \mathrm{~mol} / \mathrm{kg}$, but the aggregation process can be easily shifted to higher temperatures by increasing the salt concentration. In the present paper, we take advantage of this peculiar behavior to design a copolymer with schizophrenic gelling properties. For this purpose, side-chains of poly(N-isopropylacrylamide) (PNIPAM), characterized by a Lower Critical Solution Temperature (LCST) in water, were grafted on the alginate backbone. Working in semi-dilute solutions, we show by coupling DSC and viscoelastic measurements that ALG-g-PNIPAM solutions are able to form gels either by cooling or heating depending on the ionic environment. As the aggregation process of ALG and PNIPAM depends mainly and respectively on the nature of the cations and anions, the choice of the salt is then critical to control the self-assembly behavior and the gel properties. Moreover, as the gelation process of alginates driven by the aggregation of mannuronic sequences is characterized by a large hysteresis of 20-30 ${ }^{\circ} \mathrm{C}$ between gelling and melting, both ALG and ALG-g-PNIPAM polymers offer a large versatility not only in terms of salt (nature and concentration) but also in preparation history as different states (sol or gel) can be obtained at room temperature.

Keywords: alginate, poly( $N$-isopropylacrylamide), thermo-responsive, schizophrenic behavior, associating polymers, graft copolymers. 


\section{INTRODUCTION}

Alginate is a water-soluble linear polysaccharide consisting of 1-4 linked $\alpha$-L-guluronic $(\mathrm{G})$ and $\beta$-D-mannuronic (M) acid residues arranged in a non-regular blockwise pattern of varying proportions of homopolymeric GG, MM and heteropolymeric alternating MG sequences. ${ }^{1-3}$ Alginates are one of the main structural components in marine brown algae, and like pectins in plants, they play an important physiological role in the intercellular matrix forming hydrogels in the presence of divalent cations and bringing mechanical strength and flexibility. ${ }^{4}$ For alginates and pectins the gelation properties are induced by G-blocks (guluronic in alginates and galacturonic in pectins) which are able to bind cooperatively divalent cations forming the so-called egg-box model early described by Grant et al.. ${ }^{5}$ This intrinsic ability to form ionotropic gels in the presence of multivalent cations, combined with their specific biological properties, biocompatibility and low toxicity, have lead to important developments in food, medicine and pharmacy. For instance, their gelling, viscosifying and stabilizing properties have been used for decades to improve and modify the texture of foods or to prepare wound dressing or dental impression materials. ${ }^{6-9}$ There is actually a growing literature dealing with applications of alginate in drug release or tissue engineering where they form very useful membranes and scaffolds. ${ }^{10-15}$

As many other polysaccharides like hyaluronic acid, dextran, carboxymethylcellulose or chitosan, alginates are also considered as an important polymeric platform for developing thermoresponsive assemblies that can be used on purpose for biomedical applications like drug delivery or tissue engineering. ${ }^{16-20}$ For instance, alginates can be modified with polymer precursors characterized by a Lower Critical Solution Temperature (LCST) in water, like poly(ethylene oxide-co-propylene oxide), ${ }^{21-22}$ poly(oligo ethylene glycol methacrylate), ${ }^{23}$ poly ( $N$-vinyl caprolactam), ${ }^{24}$ or poly $(N \text {-isopropylacrylamide })^{25-27}$ (PNIPAM) in order to design temperature responsive micelles or 
vesicles for controlled drug delivery or copolymer solutions with sol/gel properties paving the way to injectable hydrogels and 3D cell culture. Although ionotropic gels formed by the complexation of alginates with multivalent cations are almost temperature independent, we have recently shown that alginates having a high mannuronic content (high-M) can form thermotropic gels upon cooling when they were studied at high ionic strength in the presence of monovalent cations. For instance, the cold gelation that was observed just below $0{ }^{\circ} \mathrm{C}$ for $\left[\mathrm{K}_{2} \mathrm{CO}_{3}\right]=0.2 \mathrm{~m}$ can be shifted to higher temperatures by increasing the salt concentration: $\mathrm{T}_{\mathrm{as}}=23{ }^{\circ} \mathrm{C}$ with $\left[\mathrm{K}_{2} \mathrm{CO}_{3}\right]=0.5 \mathrm{~m}$. The formation of these assemblies observed during cooling between mannuronic sequences was assumed to follow a UCST behavior (Upper Critical Solution Temperature) with a nucleation and growth mechanism responsible for the large hysteresis observed between gelling and melting temperatures.

Considering this specific property of high-M alginates, and concurrently to our initial strategy of developing injectable hydrogels, the goal of this work was to investigate the schizophrenic thermoresponsive behavior that can be developed by grafting LCST PNIPAM side-chains onto a high-M alginate backbone (see ALG- $g$-PNIPAM in Figure 1).
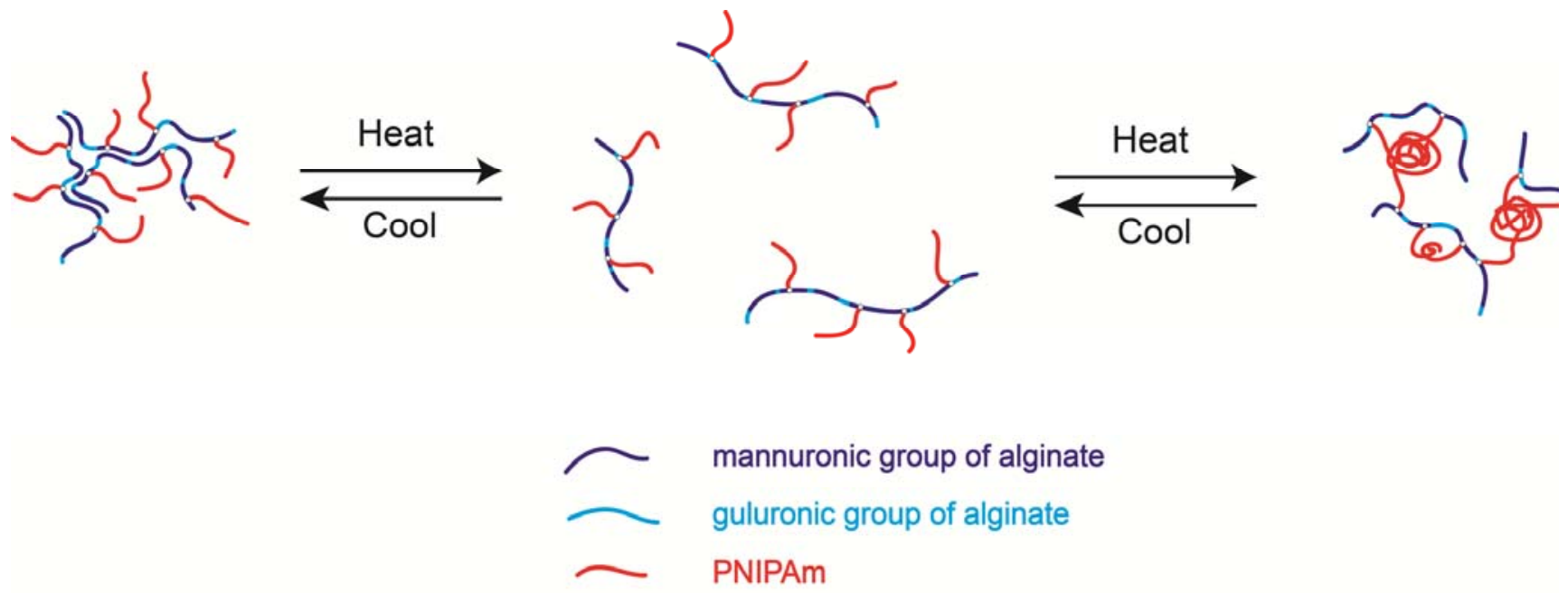

Figure 1. Schematic representation of the schizophrenic behavior of ALG-g-PNIPAM in aqueous solution of potassium salts as a function of temperature. 
In order to deliver a clear and progressive message concerning these opposite sol/gel transitions, the following discussion is organized into three main parts considering: 1) the cold gelling process of high-M alginate (ALG) solutions with the impact of polymer and salt concentrations on the association temperature and hysteresis, 2) the hot gelation in pure water of alginates modified with PNIPAM side-chains (ALG-g-PNIPAM), in these conditions only PNIPAM grafts reversibly self-associate by changing the temperature, and 3) the superposition of the two mechanisms, cold and hot gelling, when various potassium salts are added into the ALG-g-PNIPAM solution.

\section{EXPERIMENTAL SECTION}

\section{Materials}

$N$-isopropylacrylamide (NIPAM, Aldrich), cysteamine hydrochloride (AET $\cdot \mathrm{HCl}$, Fluka), potassium peroxodisulfate (KPS, Aldrich), 1-Ethyl-3-(3-dimethylaminopropyl)carbodiimide (EDCI, Aldrich) and N-hydroxysuccinimide (NHS, Fluka) were used as received. Sodium alginate (ALG) was kindly provided by Brothier Laboratories (Fontevraud-l'Abbaye, France). All the inorganic salts, potassium carbonate $\left(\mathrm{K}_{2} \mathrm{CO}_{3}\right.$ from Aldrich), potassium chloride ( $\mathrm{KCl}$ from Fluka), sodium chloride ( $\mathrm{NaCl}$ from Fluka), lithium chloride ( $\mathrm{LiCl}$ from Aldrich) and potassium thiocyanate (KSCN from Aldrich) were used as received without further purification. All organic solvents were analytical grade and water was purified with a Millipore system combining inverse osmosis membrane (Milli RO) and ion exchange resins (Milli Q) for synthesis and purification.

\section{Synthesis of ALG-g-PNIPAM}

The synthesis of thermoresponsive alginates was performed according to a two-step process, originally developed with synthetic architectures ${ }^{28-30}$ and since widely extended to a wide variety of 
polysaccharides. $^{21,31-33}$ Typically, PNIPAM telomer was first synthesized through free radical polymerization, as described elsewhere. ${ }^{34}$ Then, the copolymer ALG- $g$-PNIPAM was obtained by coupling amino-terminated telomer with carboxylic group in alginate. The process is illustrated in Figure 2 and the detailed procedure is described in supporting information.<smiles>C=CC(=O)NC(C)C</smiles>

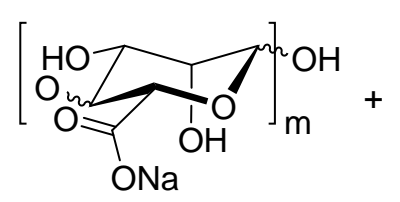<smiles>CCC(SCCN)C(=O)NC(C)C</smiles><smiles>CC(=O)ONSc1ccccc1</smiles><smiles>CCCC(C)C(=O)NC(C)C</smiles>

Figure 2. Two-step synthesis of graft copolymer ALG-g-PNIPAM.

The ${ }^{1} \mathrm{H}$ NMR spectra of ALG, PNIPAM as well as ALG- $g$-PNIPAM are given in supporting information (Figure S1) and their macromolecular characteristics are reported in Table 1.

Table 1 Characteristics of polymers

\begin{tabular}{ccccccc}
\hline & $\begin{array}{c}\boldsymbol{M}_{\mathbf{n}} \\
\mathbf{k g} / \mathbf{m o l}\end{array}$ & $\begin{array}{c}\boldsymbol{M}_{\mathbf{w}} \\
\mathbf{k g} / \mathbf{m o l}\end{array}$ & $\boldsymbol{D}$ & $\mathbf{M} / \mathbf{G}^{\mathbf{a}}$ & $\begin{array}{c}\text { Weight composition } \\
\text { PNIPAM/ALG } \\
\text { (wt/wt) }\end{array}$ & $\begin{array}{c}\text { Grafting density } \\
\text { PNIPAM/ALG } \\
\text { (mol/mol) }^{\mathbf{b}}\end{array}$ \\
\hline ALG & 60 & 134 & 2.2 & 1.6 & - & - \\
\hline PNIPAM telomer & 14 & 22 & 1.6 & - & - & - \\
\hline ALG-g-PNIPAM & 76 & 163 & 2.1 & & $40 / 60$ & $3 / 1$ \\
\hline
\end{tabular}

\footnotetext{
a,b determined by ${ }^{1} \mathrm{H}$ NMR at 80 and $25{ }^{\circ} \mathrm{C}$, respectively.
} 


\section{Size exclusion chromatography (SEC)}

Experiments were carried out with two different chromatographic systems. The first one, which was applied to the absolute characterization of polymer samples, is a Viscotek triple detector (TDA 302) equipped with three columns (OH-pak). During the analysis carried out at $28{ }^{\circ} \mathrm{C}$ in aqueous media, the flow rate was controlled at $0.6 \mathrm{~mL} \cdot \mathrm{min}^{-1}$ using $0.2 \mathrm{M} \mathrm{NaNO}_{3}$ as mobile phase. The molar masses were derived from a universal calibration curve based on Pullulan standards from Sopares (OmniSEC software). The other chromatographic system from Waters is equipped with similar Shodex OH-pak columns thermostated at $10{ }^{\circ} \mathrm{C}$ and a differential refractometer (Shimadzu RID-10A). This system was mainly used to follow, without purification, the conversion of the reactions. The flow rate was controlled at $0.90 \mathrm{~mL} \cdot \mathrm{min}^{-1}$ with $0.5 \mathrm{M} \mathrm{LiNO}_{3}$ as mobile phase.

\section{Preparation of polymer solutions}

All the studies were performed with semi-dilute solutions, either in pure water or in salted media. For each solution, the polymer was allowed to dissolve in the salted medium on a shaking table (250 rpm) at room temperature for at least $24 \mathrm{~h}$, until homogeneous solutions were obtained. The polymer concentrations are given in weight percentage $(w t \%)$ and the salt concentration is expressed in moles of salt per $\mathrm{kg}$ of solution $(m)$.

\section{Nuclear magnetic resonance (NMR)}

The composition of the copolymer was characterized with a Bruker Avance III HD spectrometer operating at $400 \mathrm{MHz}$ for ${ }^{1} \mathrm{H}$, using a standard $5 \mathrm{~mm}$ broadband Smart probe at $25{ }^{\circ} \mathrm{C}$. Complementary analyses dedicated to ALG-g-PNIPAM self-assembly were also carried out at different temperatures using a Bruker Avance III HD spectrometer operating at $600 \mathrm{MHz}$ for ${ }^{1} \mathrm{H}$, with 32 transients, 45 degree flip angle, $2.5 \mathrm{sec}$ acquisition time, $2 \mathrm{sec}$ relaxation delay. The temperature 
control was achieved by a Bruker BCU II unit and a build in temperature control unit. The sample was allowed to equilibrate for 10 minutes at each temperature. The ${ }^{1} \mathrm{H}$ chemical shifts were referred to residual HOD peak at each temperature.

\section{Rheology}

The viscoelastic properties of ALG and ALG- $g$-PNIPAM were studied in aqueous solutions, in the semi-dilute regime, using a stress-controlled rheometer (Haake RS600) equipped with a cone/plate geometry (diameter $35 \mathrm{~mm}$, angle 2, truncature $104 \mu \mathrm{m}$ ). The experiments were performed in the linear viscoelastic regime which was established for each sample by a stress sweep at $1 \mathrm{~Hz}$. The temperature was controlled by a high power Peltier system that provides fast and precise adjustment of the temperature during heating and cooling stages. Typically, the experimental conditions were fixed at constant shear stress $(2 \mathrm{~Pa})$ and frequency $(1 \mathrm{~Hz})$. According to a previous study ${ }^{35}$, a specific procedure was applied in order to remove the history of the sample (storage and preparation). For that purpose the sample was first heated to $60{ }^{\circ} \mathrm{C}$ (step 1) and then cooled from 60 to $2{ }^{\circ} \mathrm{C}$ (step 2) at a constant rate. Then, after $10 \mathrm{~min}$ at $2{ }^{\circ} \mathrm{C}$, the sample was heated again from 2 to $60{ }^{\circ} \mathrm{C}$ (step 3) and immediately cooled from 60 to $2{ }^{\circ} \mathrm{C}$ (step 4). Heating and cooling scans were performed at $2{ }^{\circ} \mathrm{C} \cdot \min ^{-1}$ for all the samples, but slower rates $\left(0.5\right.$ and $\left.1{ }^{\circ} \mathrm{C} \cdot \mathrm{min}^{-1}\right)$ were also used to investigate the impact of heating and cooling procedures on the sol/gel transition. The reproducibility was checked for each experiment and a particular care was taken to avoid the drying of the sample by using a homemade cover which prevents from water evaporation during analysis. This was verified with the equivalence of steps 2 and 4 . In the following, dynamic moduli ( $G^{\prime}$ and $\left.G^{\prime \prime}\right)$ as well as complex viscosity $\left(\eta^{*}\right)$ will be plotted between 2 and $60^{\circ} \mathrm{C}$ using only steps 2 and 3 . 


\section{Differential Scanning Calorimetry (DSC)}

The phase transition of copolymers in aqueous solution was investigated by Differential Scanning Calorimetry using a DSC Q200 from TA instrument. Polymer solutions (ca. $80 \mathrm{mg}$ ), equilibrated with a reference filled with the same quantity of solvent, were submitted to temperature cycles between 2 and $60{ }^{\circ} \mathrm{C}$. As for rheology experiments, the heating and cooling rates were fixed at $2{ }^{\circ} \mathrm{C} \cdot \mathrm{min}^{-1}$. For each sample, the standard procedure was the following: (i) cooling from 20 to $2{ }^{\circ} \mathrm{C}$; (ii) isotherm at $2{ }^{\circ} \mathrm{C}(10 \mathrm{~min})$; (iii) step 1 , heating from 2 to $60^{\circ} \mathrm{C}$; (iv) isotherm at $60^{\circ} \mathrm{C}(10 \mathrm{~min})$; (v) step 2, cooling from 60 to $2{ }^{\circ} \mathrm{C}$; (vi) isotherm at $2{ }^{\circ} \mathrm{C}(10 \mathrm{~min})$; (vii) step 3, heating from 2 to $60{ }^{\circ} \mathrm{C}$. Only steps 2 and 3 will be used for the data analysis.

\section{RESULTS AND DISCUSSION}

\section{Cold Gelation of Alginates}

\section{Sol/gel transition of ALG solutions}

As discussed previously, alginates are widely known to viscosify and to form gels either by lowering the $\mathrm{pH}$, or by adding multivalent cations that induce strong zip-complexes between the G-blocks. ${ }^{3,36}$ Nevertheless these are not the only ways to prepare alginate gels in aqueous media and we have recently reported that alginates with a high mannuronic content (high-M) were also able to reversibly self-associate at low temperature in the presence of potassium salts. ${ }^{35}$ This behavior, that has been initially highlighted with potassium carbonate, is displayed in Figure $\mathbf{3}$ with an alginate solution $\left(\mathrm{C}_{\mathrm{p}}=5 \mathrm{wt} \%\right)$ prepared in $\mathrm{KCl} 0.6 \mathrm{~m}$. Starting at high temperature $\left(\mathrm{T}=60{ }^{\circ} \mathrm{C}\right)$, with a viscous solution $\left(G^{\prime \prime}>G^{\prime}\right)$, the dynamic moduli continuously increase during cooling down to $15^{\circ} \mathrm{C}$ where a sharp sol/gel transition takes place. At $\mathrm{T}=2{ }^{\circ} \mathrm{C}$ the elastic modulus is more than 5 times higher than the loss 
modulus and it is almost independent of the frequency in the range explored $\left(10^{-1}-10^{1} \mathrm{~Hz}\right)$. The gelation process is reversible with an important hysteresis as the initial viscoelastic properties are recovered only above $40{ }^{\circ} \mathrm{C}$. This viscoelastic loop, that can be repeated as many times as wanted, weakly depends on the rate of cooling/heating, at least in the range investigated $\left(0.5\right.$ to $2{ }^{\circ} \mathrm{C} / \mathrm{min}$; see Figure S2 in supporting information). The crossover between G' and G" will be used in the following to define the sol/gel transition temperature as this simple criterion matches fairly well the critical conditions defined by Winter as the point where $\tan \delta=\mathrm{G}$ ' $/ \mathrm{G}$ ' becomes independent of frequency (see Figure S2 in supporting information). ${ }^{37}$ Using the experimental results reported in Figure 3, $\mathrm{T}_{\mathrm{s}-\mathrm{g}}=12{ }^{\circ} \mathrm{C}$ and $\mathrm{T}_{\mathrm{g}-\mathrm{s}}=38{ }^{\circ} \mathrm{C}$ can be determined for the sol/gel and the gel/sol transition temperatures, respectively.

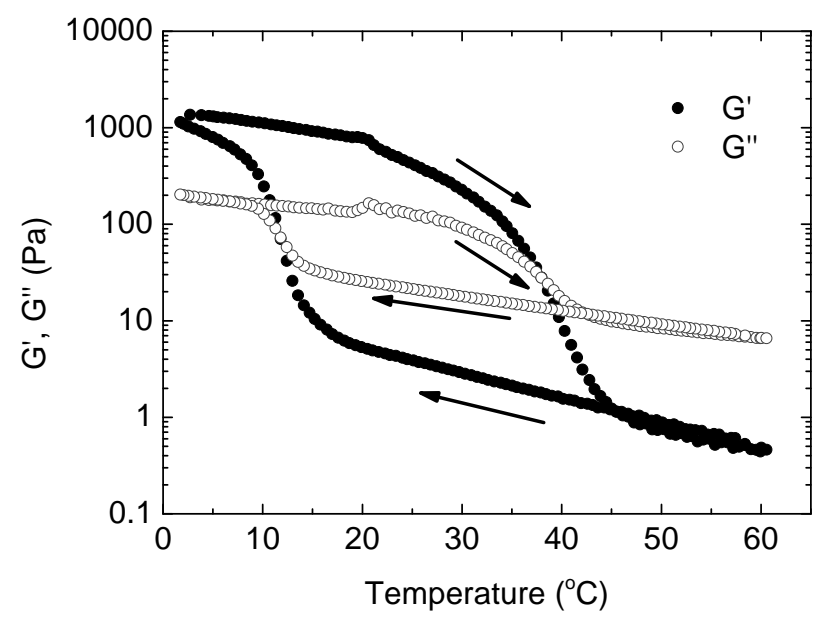

\section{Figure 3}

Temperature dependence of elastic ( $\mathrm{G}^{\prime}$; filled symbol) and loss (G"; hollow symbol) moduli of ALG solution $\left(C_{p}=5 \mathrm{wt} \%,[\mathrm{KCl}]=0.6 \mathrm{~m}\right)$. Heating and cooling rates $=2{ }^{\circ} \mathrm{C} \cdot \mathrm{min}^{-1}, f=1 \mathrm{~Hz}$.

The association process between alginate chains, which is triggered at relatively high salt concentration and low temperature, results in the formation of an elastic gel if the polymer concentration is high enough. In the case of this alginate sample, this situation is observed for $C_{p} \geq 2$ wt $\%$. At lower concentration $\left(\mathrm{C}_{\mathrm{p}}=1 \mathrm{wt} \%\right)$, the solution retains a predominant viscous character at low temperature despite the large increase in dynamic moduli below $16{ }^{\circ} \mathrm{C}$ (see Figure S3 in supporting information). In order to get a quick and quantitative understanding of the rheological behavior, the viscoelastic data can also be plotted by using the complex viscosity $\left(\eta^{*}\right)$ as a single parameter (see 
Figure 4). Indeed, as $\eta^{*}=\sqrt{\left(G^{\prime} / \omega\right)^{2}+\left(G^{\prime \prime} / \omega\right)^{2}}$, the complex viscosity can be identified to the Newtonian viscosity in the sol regime $\left(\eta^{*}=\eta_{0}\right.$, for $\left.G^{\prime \prime}>>G^{\prime}\right)$ while it scales with the plateau modulus $\left(G_{0}\right)$ in the gel regime (for $\mathrm{G}^{\prime}>>\mathrm{G}^{\prime \prime}, \eta^{*} \cong G^{\prime} / \omega \cong G_{0} / \omega$ with $\omega=6.28 \mathrm{rad} / \mathrm{s}$ in our conditions). As shown in Figure 4, sol/gel and gel/sol transitions give rise to abrupt changes of $\eta^{*}$ versus temperature and this plot can be interestingly normalized by dividing $\eta^{*}$ by the Newtonian viscosity $\left(\eta_{0}\right)$ of the unassociated polymer solution: $\eta_{r e l}(T)=\left(\eta^{*}(T) / \eta_{0}(T)\right)$. For that purpose, the experimental data obtained in the sol regime have been fitted by the Andrade equation $\eta_{0}=A \exp \left(E_{a} / R T\right)$ in order to extrapolate the Newtonian viscosity in the whole temperature range: between 2 and $60{ }^{\circ} \mathrm{C}$ (see Figure 4).

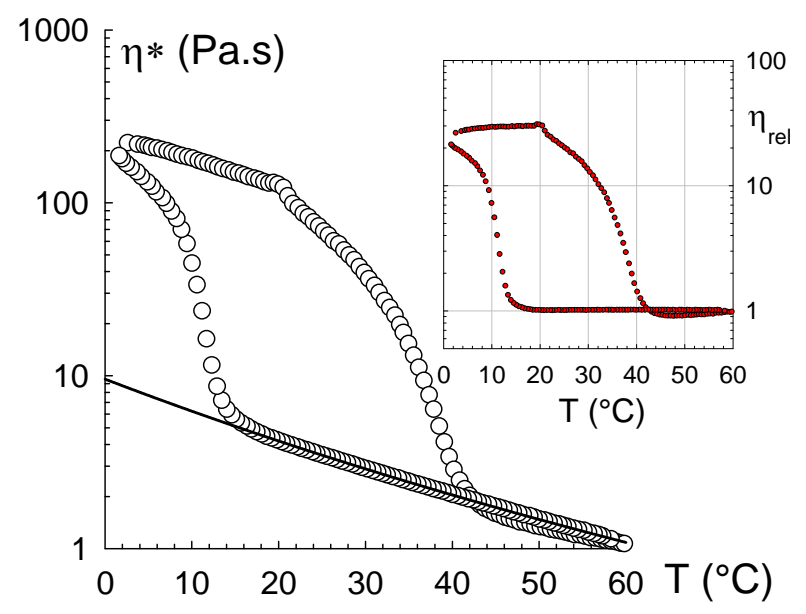

Figure 4

Temperature dependence of complex viscosity $(\eta " ; O)$ and relative viscosity $\left(\eta_{\text {rel }} ; \bigcirc\right)$ of ALG solution $\left(C_{p}=5 \mathrm{wt} \%,[\mathrm{KCl}]=0.6 \mathrm{~m}\right)$.

Heating and cooling rates $=2{ }^{\circ} \mathrm{C} \cdot \mathrm{min}^{-1}, f=1 \mathrm{~Hz}$. Andrade equation (-): $\eta_{0}=5 \cdot 5 \cdot 10^{-5} \exp (3295 / T)$

In the Andrade equation mentioned above, $A$ is a constant, $R$ is the gas constant, $T$ is the absolute temperature and $E_{\mathrm{a}}$ is the activation energy for viscous flow. All the alginate solutions investigated in this study display similar activation energies $\left(E_{\mathrm{a}}=26 \pm 2 \mathrm{~kJ} / \mathrm{mol}\right)$ which are typical of non associating polymer solution in this range of polymer concentrations. ${ }^{38}$ As shown in Figure 4 (inset), the plot of the relative viscosity $\left(\eta_{\text {rel }}\right)$ clearly emphasizes the association process with the baseline corresponding to the "sol" domain (unassociating polymer chains) and large increase of the relative viscosity as soon as the association mechanism takes place leading to the physical gelation of the solution, at least for 
concentrations higher than $1 \mathrm{wt} \%$. This normalized curve will be calculated thereafter for all the samples in order to provide an efficient comparison of their associating behavior. Moreover, the relative viscosity will be also used to define systematically the beginning of the association process observed during cooling $\left(\mathrm{T}_{\mathrm{as}}\right)$ as well as the end of the dissociation one observed upon heating $\left(\mathrm{T}_{\mathrm{dis}}\right)$. For that purpose, the critical temperatures were determined at $\eta_{r e l}=1.1$ (10\% deviation over more than $1000 \%$ ); a criterion that can be accurately applied to all the formulations with less than $1{ }^{\circ} \mathrm{C}$ difference by comparison with lower deviation values. While viscoelastic measurements clearly highlight the macroscopic transition occurring for high-M alginates in the presence of high concentrations of potassium salt, the thermodynamic aspects of the phase transition can also be studied in a complementary manner by DSC. As previously reported, the cold gelation of high-M alginates is an exothermic process which slightly depends on the rate of cooling. ${ }^{35}$ The enthalpogram given in Figure 5, obtained with the reference solution ([ALG] $=5 \mathrm{wt} \%$ and $[\mathrm{KCl}]=0.6 \mathrm{~m}$ ) using the same cooling and heating rates $\left(2{ }^{\circ} \mathrm{C} / \mathrm{min}\right)$, displays a well-defined exothermic peak $\left(\Delta \mathrm{H}=5.5 \mathrm{~J} / \mathrm{g}_{\mathrm{ALG}}\right)$ upon cooling that starts around $\mathrm{T}_{\mathrm{as}}=10.5^{\circ} \mathrm{C}$ with a maximum located at $\mathrm{T}_{\mathrm{M}-\mathrm{Cool}}=8.8^{\circ} \mathrm{C}$.

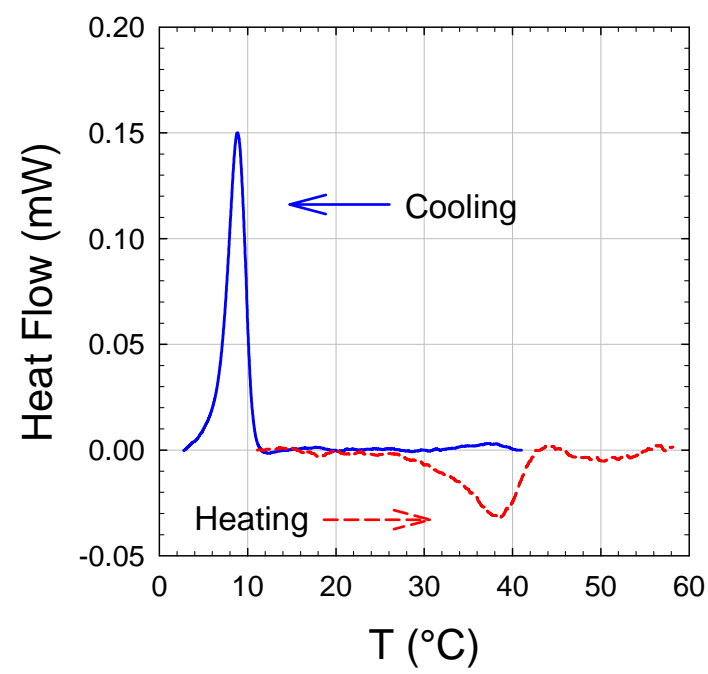

\section{Figure 5}

Thermograms of

ALG solution $\left(C_{p}=5 \mathrm{wt} \%,[\mathrm{KCl}]=0.6 \mathrm{~m}\right)$.

Cooling and heating rates $=2{ }^{\circ} \mathrm{C} \cdot \mathrm{min}^{-1}$.

By heating the solution from $2{ }^{\circ} \mathrm{C}$ back to $60{ }^{\circ} \mathrm{C}$, a much broader endotherm is observed for the dissociation process that extends from about $30{ }^{\circ} \mathrm{C}$ up to $\mathrm{T}_{\mathrm{dis}}=44{ }^{\circ} \mathrm{C}$ with a maximum located at 
$\mathrm{T}_{\mathrm{M}-\mathrm{Heat}}=37.6^{\circ} \mathrm{C}$. Such large hysteresis and the transition enthalpy are in good agreement with our previous data reported with similar alginate samples studied in potassium carbonate solutions. ${ }^{35}$ This phenomenon is attributed to the self-association of M-blocks into clusters following a nucleation and growth process. Even if the first events of self-assembling and self-dissociation taking place upon cooling and heating, respectively, are more easily detected by rheology rather than by calorimetry, the sol/gel transition temperatures are very close to the maxima of enthalpograms (see Table 2) pointing out the tight correlation between the formation of specific interactions and the dramatic increase of viscoelastic properties.

\section{Influence of salt concentration}

From complementary experiments performed with the former solution $\left(\mathrm{C}_{\mathrm{p}}=5 \mathrm{wt} \%\right.$ and $\left.[\mathrm{KCl}]=0.6 \mathrm{~m}\right)$ by adding either a hydrogen bonding competitor ([urea]=1 m) or surfactant (sodium dodecyl sulfate: $\left.[\mathrm{SDS}]=(5-20) \cdot 10^{-3} \mathrm{~m}\right)$, we do not really observed significant modifications of the gelation process, neither on the transition temperatures nor on the absolute values of the dynamic moduli (see Figure S4 in Supporting Information). These results highlight that hydrophobic interactions as well as hydrogen bonds are not the key interactions involved in the association mechanism of alginates and they emphasize the central role of ionic interactions. This is emphasized in Figure 6, where the relative viscosity of the alginate solution $\left(\mathrm{C}_{\mathrm{p}}=5 \mathrm{wt} \%\right)$ has been studied with different $\mathrm{KCl}$ concentrations. Working in the temperature range 2 to $60{ }^{\circ} \mathrm{C}$, the gelation process begins to be observed for $\mathrm{KCl}$ concentration of $0.4 \mathrm{~m}$. In this case the association starts at very low temperature $\left(\mathrm{T}_{\mathrm{as}}=5.5{ }^{\circ} \mathrm{C}\right.$ ) with a gelation threshold around $\mathrm{T}_{\mathrm{s}-\mathrm{g}}=3{ }^{\circ} \mathrm{C}$ and a dissociation taking place at higher temperature with a similar hysteresis $\left(\mathrm{T}_{\mathrm{g}-\mathrm{s}}-\mathrm{T}_{\mathrm{s}-\mathrm{g}}=25-30{ }^{\circ} \mathrm{C}\right)$ as reported with the previous solution. By increasing the $\mathrm{KCl}$ concentration, the association temperature is shifted to higher temperatures, up to 19-20 ${ }^{\circ} \mathrm{C}$ for $\mathrm{KCl} 0.7 \mathrm{~m}$, with a similar shift for the dissociation process. 


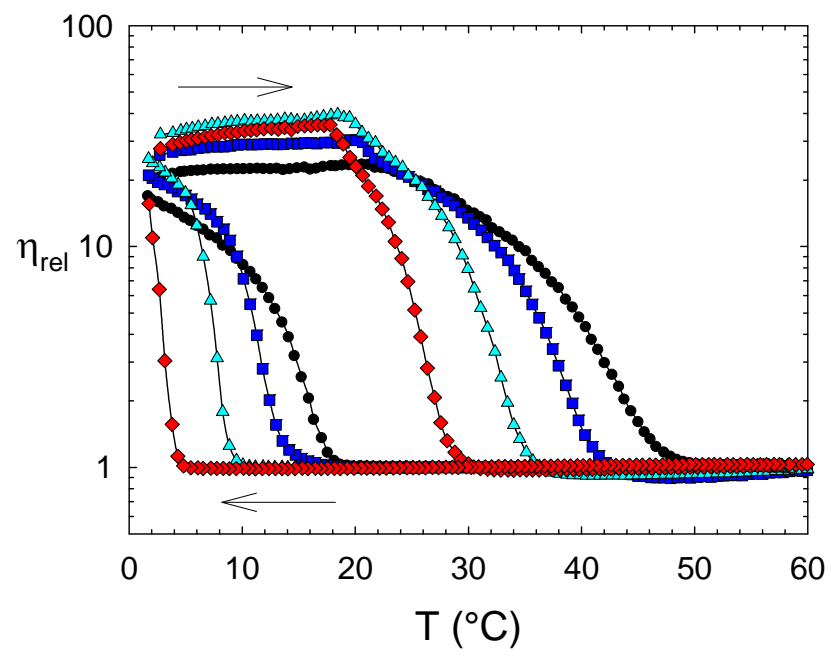

\section{Figure 6}

Temperature dependence of relative viscosity of alginate aqueous solution $\left(C_{p}=5 \mathrm{wt} \%\right)$ with different $\mathrm{KCl}$ concentrations:

$0.4 \mathrm{~m}(\diamond) ; 0.5 \mathrm{~m}(\triangle) ; 0.6 \mathrm{~m}(\square)$ and $0.7 \mathrm{~m}(\bullet)$ (heating and cooling rate $=2{ }^{\circ} \mathrm{C} \cdot \mathrm{min}^{-1}, \mathrm{f}=1 \mathrm{~Hz}$ ).

DSC experiments performed in similar conditions with the same solutions are in quantitative agreement with rheology for the transition temperatures and show only a slight decrease of the enthalpy with increasing salt concentrations (see Table 2). DSC also demonstrates that alginates can undergo transition at lower $\mathrm{KCl}$ concentration $(0.3 \mathrm{~m}$ for instance) if the solution is cooled below $0{ }^{\circ} \mathrm{C}$.

Table 2. Transition temperatures of alginate solutions $\left(C_{p}=5 \mathrm{wt} \%\right)$ as a function of $\mathrm{KCl}$ concentration.

\begin{tabular}{|c|c|c|c|c|c|c|c|c|c|}
\hline \multirow{3}{*}{$\begin{array}{c}\mathrm{C}_{\mathrm{p}} \\
\mathrm{wt} \%\end{array}$} & \multirow{3}{*}{$\begin{array}{c}{[\mathrm{KCl}]} \\
(\mathrm{m})\end{array}$} & \multicolumn{5}{|c|}{ Rheology } & \multicolumn{3}{|c|}{ DSC } \\
\hline & & \multicolumn{2}{|c|}{ Cooling } & \multicolumn{2}{|c|}{ Heating } & \multirow{2}{*}{$\begin{array}{c}\Delta \mathrm{T} \\
\mathrm{T}_{\mathrm{g} / \mathrm{s}}-\mathrm{T}_{\mathrm{s} / \mathrm{g}} \\
{ }^{\circ} \mathrm{C}\end{array}$} & \multicolumn{2}{|c|}{ Cooling } & \multirow{2}{*}{$\begin{array}{c}\text { Heating } \\
\mathrm{T}_{\text {M-Heat }} \\
{ }^{\circ} \mathrm{C} \\
\end{array}$} \\
\hline & & $\begin{array}{c}\mathrm{T}_{\mathrm{s} / \mathrm{g}} \\
{ }^{\circ} \mathrm{C}\end{array}$ & $\begin{array}{l}\mathrm{T}_{\mathrm{as}} \\
{ }^{\circ} \mathrm{C}\end{array}$ & $\begin{array}{l}\mathrm{T}_{\mathrm{g} / \mathrm{s}} \\
{ }^{\circ} \mathrm{C}\end{array}$ & $\begin{array}{l}\mathrm{T}_{\mathrm{dis}} \\
{ }^{\circ} \mathrm{C}\end{array}$ & & $\begin{array}{c}\mathrm{T}_{\mathrm{M}-\mathrm{Cool}} \\
{ }^{\circ} \mathrm{C}\end{array}$ & $\begin{array}{c}\Delta \mathrm{H}_{\mathrm{gel}} \\
\mathrm{J} / \mathrm{g}_{\mathrm{ALG}}\end{array}$ & \\
\hline \multirow{7}{*}{5} & 0 & / & / & / & / & / & / & / & / \\
\hline & 0.2 & 1 & 1 & 1 & 1 & 1 & 1 & 1 & 1 \\
\hline & 0.3 & 1 & 1 & 1 & 1 & 1 & -3.2 & 6.7 & 20.2 \\
\hline & 0.4 & 3.0 & 5.5 & 26.0 & 30 & 23.0 & 0.7 & 6.0 & 26.9 \\
\hline & 0.5 & 7.5 & 10.5 & 32.5 & 37 & 25.0 & 5.4 & 6.2 & 33.2 \\
\hline & 0.6 & 12.0 & 14.7 & 38.0 & 44 & 26.0 & 8.8 & 5.5 & 37.6 \\
\hline & 0.7 & 15.0 & 19.3 & 41.7 & 50 & 26.7 & 14.9 & 5.5 & 44.7 \\
\hline $\bar{~} 1$ & \multirow{6}{*}{0.6} & 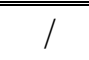 & 16.4 & $\overline{~ / 1}$ & $\bar{~} 51.1$ & $\overline{~ / 1}$ & 10.1 & 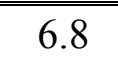 & 44.5 \\
\hline 2 & & 13.5 & 15.0 & 38.0 & 46.8 & 24.5 & 10.1 & 7.0 & 43.9 \\
\hline 3 & & 13.0 & 15.3 & 40.5 & 44.9 & 27.5 & 9.8 & 6.2 & 41.5 \\
\hline 4 & & 11.3 & 13.0 & 39.5 & 44.2 & 28.2 & 8.9 & 5.9 & 39.2 \\
\hline 5 & & 12.0 & 14.7 & 38.0 & 44.0 & 26.0 & 8.8 & 5.5 & 37.6 \\
\hline 6 & & 10.5 & 12.9 & 37.0 & 40.9 & 26.5 & 8.7 & 5.4 & 37.6 \\
\hline
\end{tabular}




\section{Hot Gelation of Modified Alginates}

The introduction of LCST polymer sequences (blocks or side-chains) within a hydrophilic macromolecular architecture has been a hot topic over the past 25 years as these systems provide an original response to the design of responsive aqueous formulations of paramount interest in many different fields such as oil recovery, cosmetics or biomedicine. Mostly prepared from synthetic polymers $^{28,30,39-40}$, their development has been extended to biopolymers, mainly polysaccharides, especially for biomedical applications. ${ }^{16-20}$ This is the case of alginates that have been modified with various LCST polymers like poly(alkylene oxide) or poly(N-alkylacrylamide) in order to develop hot gelling properties. ${ }^{21-22,}$ 25-27 Such behavior is highlighted in Figure 7 with the ALG-g-PNIPAM sample studied at $\mathrm{C}_{\mathrm{p}}=5 \mathrm{wt} \%$ in pure water where alginate itself does not self-associate. In these conditions, the solution which is originally viscous at low temperature undergoes a sol/gel transition by heating with a clear deviation of dynamic moduli, as well as the relative viscosity (see Figure S5 in supporting information), at $\mathrm{T}_{\mathrm{as}}=34^{\circ} \mathrm{C}$ and a gelation threshold $\left(\mathrm{G}^{\prime}=\mathrm{G}^{\prime \prime}\right)$ at $\mathrm{T}_{\mathrm{s} / \mathrm{g}}=44^{\circ} \mathrm{C}$. Here, we can notice that the association temperature is in perfect agreement with the beginning of the phase transition $\left(\mathrm{T}_{\mathrm{as}}=34^{\circ} \mathrm{C}\right)$ that can be determined by DSC on an equivalent solution of PNIPAM precursor. Moreover, contrary to the thermogelation process of un-modified alginates in salted media, the self-assembling behavior induced by the micro-phase separation of PNIPAM side chains is reversible with practically no hysteresis as we can see from both viscoelasticity (Figure 7) and DSC experiments (see Figure S6 in supporting information). By comparison with the transition enthalpy of the PNIPAM precursor $\left(\Delta \mathrm{H}=40 \mathrm{~J} / \mathrm{g}_{\mathrm{NIPAM}}\right)$, the heat release occurring during the phase transition of the graft copolymer solution is quantitatively lower $\left(\Delta \mathrm{H}=28 \mathrm{~J} / \mathrm{g}_{\mathrm{NIPAM}}\right)$. This variation, which has already been observed with alginates modified with other LCST stickers like poly(ethylene oxide-co-propylene oxide) (ALG-PEPO), ${ }^{21}$ as well as with other synthetic graft copolymers, ${ }^{41}$ 
mirrors a weaker dehydration process related to steric hindrance and/or electrostatic repulsions induced by the alginic backbone.

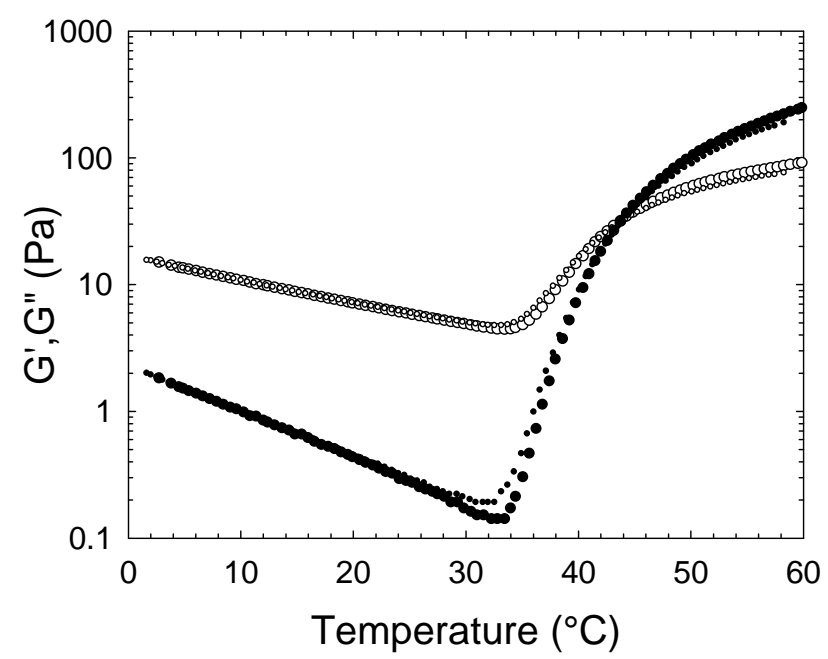

Figure 7

Temperature dependence of dynamic modulus G' (filled symbol) and G" (hollow symbol) of ALG- $g$-PNIPAM aqueous solution $\left(\mathrm{C}_{\mathrm{p}}=5 \mathrm{wt} \%\right.$, $\left.\mathrm{H}_{2} \mathrm{O}\right)$ upon heating $(\bigcirc \mathrm{O})$ and cooling $(\bullet \circ)$ (heating and cooling rate $=2{ }^{\circ} \mathrm{C} \cdot \mathrm{min}^{-1}, \mathrm{f}=1 \mathrm{~Hz}$ ).

Complementary experiments have been carried out by ${ }^{1} \mathrm{H}$ NMR as a function of temperature. From the series of NMR spectra obtained between 20 and $60{ }^{\circ} \mathrm{C}$ (Figure 8), we can see that the characteristic signals of NIPAM units, methyl ( 1 ppm) and methine (3.8 ppm), sharply decrease within the interval $35-50{ }^{\circ} \mathrm{C}$ in good agreement with viscoelastic and DSC data.
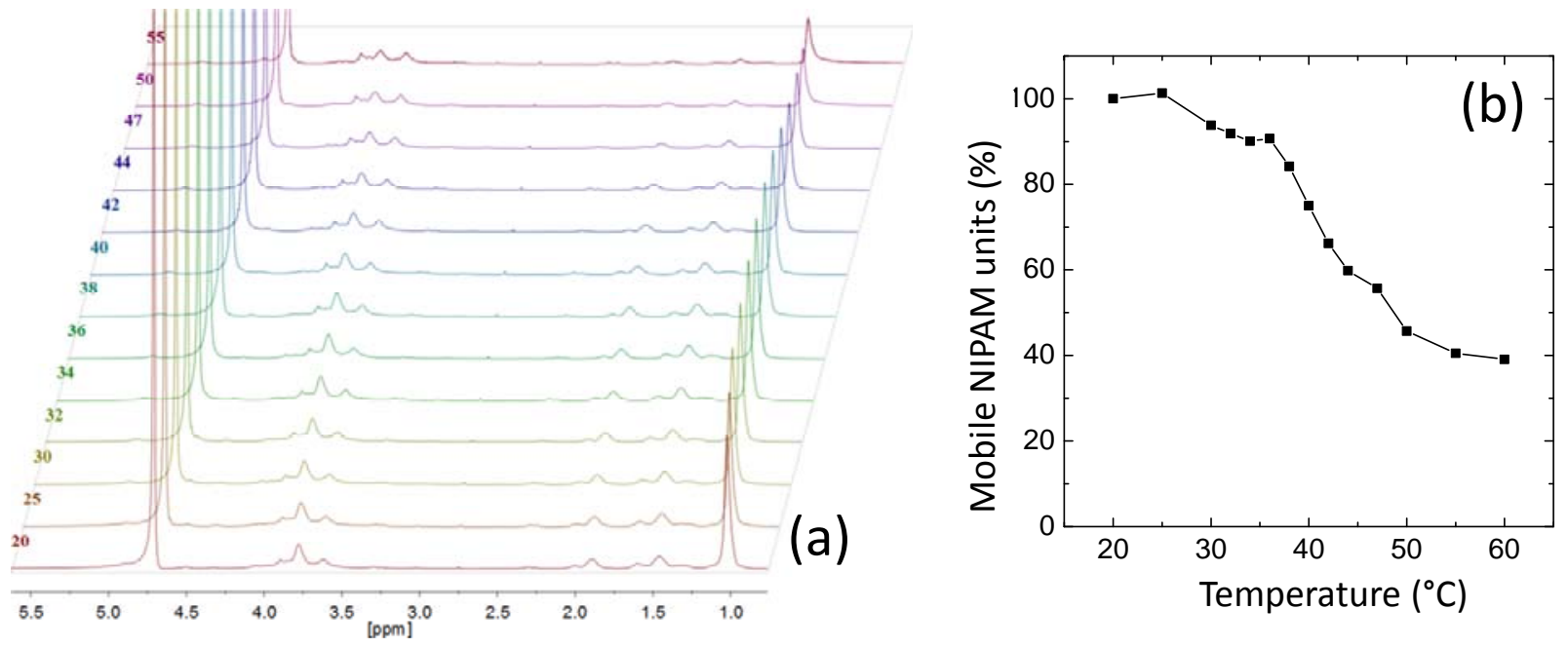

Figure 8. (a) Temperature variation of ${ }^{1} \mathrm{H}$ NMR spectrum of ALG- $g$-PNIPAM in $\mathrm{D}_{2} \mathrm{O}$ solution $\left(\mathrm{C}_{\mathrm{p}}=5\right.$ $\mathrm{wt} \%$ ) and (b) temperature dependence of mobile NIPAM units within the graft copolymer. 
This feature, which has been widely reported with PNIPAM copolymers or gels, ${ }^{34,}{ }^{42-43}$ can be assigned to the formation of a solid-like rich-PNIPAM phase where the motions of the functional groups are strongly reduced. Quantitatively it appears that around 50 to $60 \%$ of NIPAM units have lost their mobility at $60{ }^{\circ} \mathrm{C}$, within the timescale of the NMR experiment, and strongly self-interact inside rich-PNIPAM domains. This information can be interestingly compared with the $40 \%$ decrease of the transition enthalpy that has been observed by DSC between ungrafted and grafted PNIPAM chains if we assume that the remaining fraction of mobile NIPAM units (40 to 50\%) remains hydrated in close contact with the aqueous phase due to steric hindrance imposed by the backbone.

\section{Cold and Hot Gelation of Modified Alginates}

\section{Gel/Sol/Gel transitions of ALG-g-PNIPAM}

Since high-M alginates and PNIPAM are characterized by opposite thermoresponsive behaviors in aqueous media, the main goal of this study was to couple these two precursors within the same macromolecular architecture in order to develop a versatile system able to develop antagonistic thermogelation properties. To that purpose, a first set of experiments was performed in $[\mathrm{KCl}]=0.6 \mathrm{~m}$, where both high-M alginate and PNIPAM are known to exhibit thermoresponsive properties. The results of the dynamic analysis reported in Figure 9 for a $5 \mathrm{wt} \%$ solution clearly emphasize such antagonistic behaviors, which can be discussed as follows. For this purpose we have also added in Figure 9 a schematic representation of the associations taking place at low temperature between mannuronic sequences and at high temperature between PNIPAM side-chains. Of course for the sake of simplicity, this drawing does not consider the relative size of the associative sequences nor their number of aggregations which are much larger. At high temperature $\left(\mathrm{T}=60^{\circ} \mathrm{C}\right)$, where $\mathrm{ALG}$ chains do not associate, the phase separation of PNIPAM side-chains into connecting micro-domains is 
responsible for the gel formation $\left(\mathrm{G}^{\prime}>>\mathrm{G}^{\prime \prime}\right)$ with an elastic modulus close to $1 \mathrm{kPa}$. By decreasing the temperature, the attractive interactions between PNIPAM stickers are progressively weakened, as well as the gel strength, and the association mechanism totally disappears below $26{ }^{\circ} \mathrm{C}$ when all PNIPAM side-chains recover their full solubility in the salt solution.

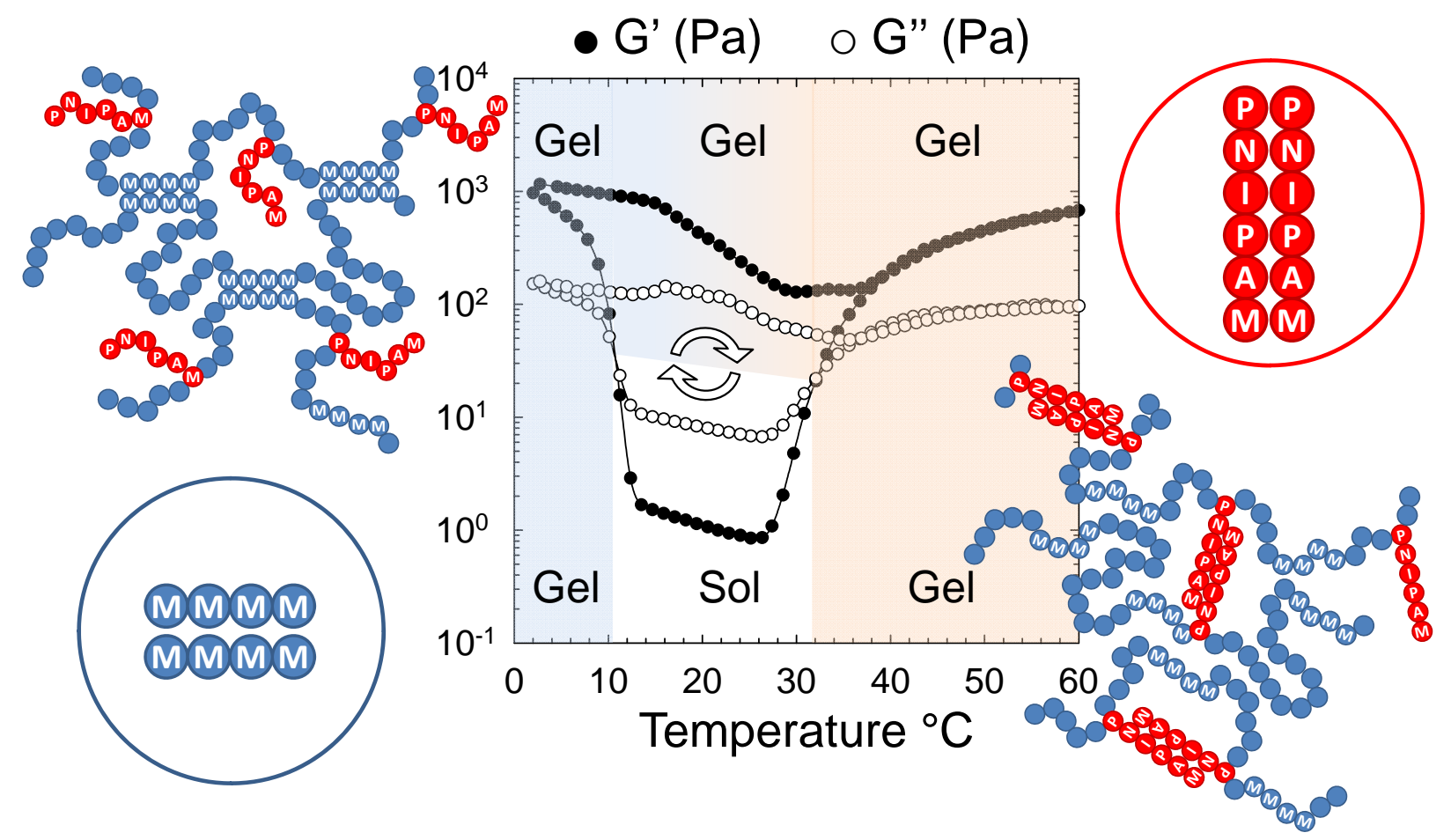

Figure 9. Temperature dependence of dynamic modulus G' (filled symbol) and G" (hollow symbol) of ALG- $g$-PNIPAM aqueous solution $\left(\mathrm{C}_{\mathrm{p}}=5 \mathrm{wt} \%,[\mathrm{KCl}]=0.6 \mathrm{~m}\right)$ upon heating and cooling (heating and cooling rate $=2{ }^{\circ} \mathrm{C} \cdot \mathrm{min}^{-1}, \mathrm{f}=1 \mathrm{~Hz}$ ). Schematic representation of the schizophrenic behavior.

Then, the solution keeps its liquid-like behavior between 26 and $14.5{ }^{\circ} \mathrm{C}$ where the association mechanism of high-M alginate chains takes over with cold gelling. As it will be discussed later, the transition temperatures measured with the graft copolymer are very close to those which can be determined separately with alginate or PNIPAM solutions. In other words, each polymer precursor works independently within the grafted structure without any strong interference with the other. Nevertheless, due to the great hysteresis of the association/dissociation process of alginates, once the 
gel is formed at low temperature, the formulation retains its elastic behavior over the entire temperature range $\left(2\right.$ to $\left.60{ }^{\circ} \mathrm{C}\right)$ as the association of PNIPAM stickers overlaps the dissociation process of alginate chains. For instance, taking into account the viscoelastic data obtained with unmodified alginates, $\mathrm{T}_{\mathrm{g} / \mathrm{s}}$ and $\mathrm{T}_{\mathrm{dis}}$ are expected at about 38 and $44{ }^{\circ} \mathrm{C}$, respectively (see Table 2), although the association of PNIPAM starts well below at $\mathrm{T}_{\mathrm{as}} \simeq 26^{\circ} \mathrm{C}$. As a consequence, by working at room temperature $\left(\mathrm{T} \cong 20{ }^{\circ} \mathrm{C}\right)$, it is possible to obtain two distinct behaviors from the same initial formulation: a viscous solution or an elastic gel, according to whether it has been prepared from high or low temperatures, respectively.

As shown in Figure 10, the dissociation process of PNIPAM stickers upon cooling, as well as the association of alginates chains, can be also easily distinguished by DSC as these transitions take place at different and well defined temperatures.

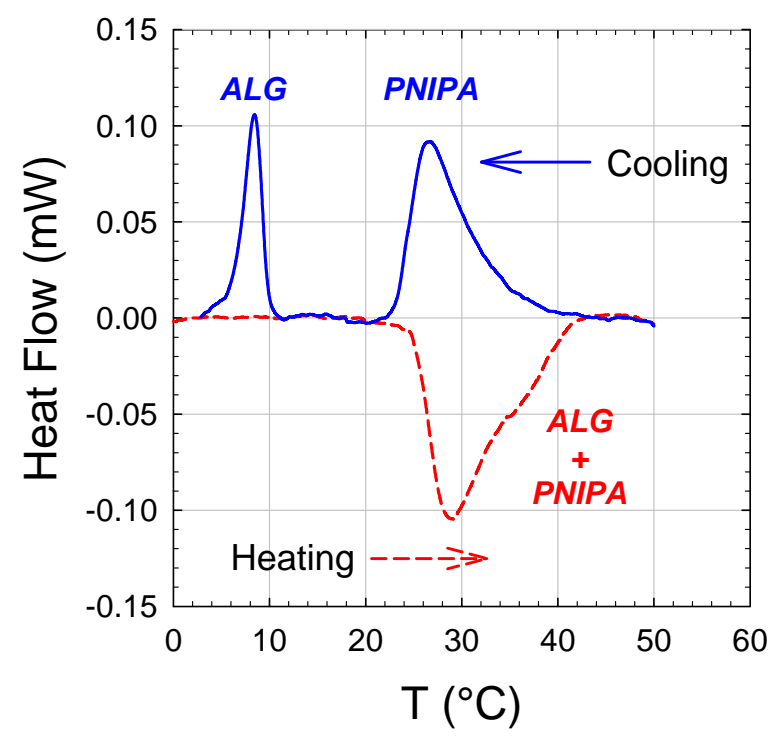

\section{Figure 10}

Thermograms of ALG- $g$-PNIPAM solution $\left(C_{p}=5 \mathrm{wt} \%,[\mathrm{KCl}]=0.6 \mathrm{~m}\right)$. Cooling and heating rates are $2^{\circ} \mathrm{C} \cdot \mathrm{min}^{-1}$.

From the exothermic signatures recorded during cooling, the characteristic temperatures as well as the enthalpies were determined and reported in Table 3. The comparison of these values with those given in Table 2 for alginate solutions clearly demonstrates that association and gelation process take place at similar temperature, whether alginate chains are grafted or not. The transition enthalpy also 
remains comparable within the limit of accuracy of the measurements. Concerning the self-assembly induced by PNIPAM stickers, the hysteresis remains weak, less than $3{ }^{\circ} \mathrm{C}$, and the transition temperatures are close to those determined from the solution of PNIPAM precursor investigated in the same conditions $\left(\mathrm{T}_{\mathrm{M}-\mathrm{Cool}}=25.4{ }^{\circ} \mathrm{C} ; \mathrm{T}_{\mathrm{M}-\mathrm{Heat}}=27.3{ }^{\circ} \mathrm{C}\right)$.

Table 3. DSC analysis: influence of the nature of salt and its concentration on the transition temperature and enthalpy of ALG- $g$-PNIPAM solutions $\left(\mathrm{C}_{\mathrm{p}}=5 \mathrm{wt} \%\right)$.

\begin{tabular}{|c|c|c|c|c|c|c|c|}
\hline \multirow{3}{*}{ Salt } & \multirow{3}{*}{$(\mathrm{m})$} & \multicolumn{3}{|c|}{ ALG } & \multicolumn{3}{|c|}{ PNIPAM } \\
\hline & & \multicolumn{2}{|c|}{ Cooling } & \multirow{2}{*}{$\begin{array}{c}\text { Heating } \\
\mathrm{T}_{\mathrm{M}-\mathrm{Heat}} \\
{ }^{\circ} \mathrm{C}\end{array}$} & \multicolumn{2}{|c|}{ Cooling } & \multirow{2}{*}{$\begin{array}{c}\text { Heating } \\
\mathrm{T}_{\mathrm{M}-\mathrm{Heat}} \\
{ }^{\circ} \mathrm{C}\end{array}$} \\
\hline & & $\begin{array}{c}\mathrm{T}_{\mathrm{M}-\mathrm{Cool}} \\
{ }^{\circ} \mathrm{C}\end{array}$ & $\begin{array}{c}\Delta \mathrm{H}_{\text {Cool }} \mid \\
\mathrm{J} / \mathrm{g}_{\mathrm{ALG}} \\
\end{array}$ & & $\begin{array}{c}\mathrm{T}_{\mathrm{M}-\mathrm{Cool}} \\
{ }^{\circ} \mathrm{C}\end{array}$ & $\begin{array}{l}\left|\Delta \mathrm{H}_{\text {Cool }}\right| \\
\mathrm{J} / \mathrm{g}_{\text {NIPAM }}\end{array}$ & \\
\hline \multirow{7}{*}{$\mathrm{KCl}$} & 0 & 1 & 1 & 1 & 34.3 & 28 & 37.0 \\
\hline & 0.2 & 1 & 1 & 1 & 32.6 & 21 & 34.5 \\
\hline & 0.3 & -4.4 & 8.3 & 15.6 & 31.3 & 25 & 32.9 \\
\hline & 0.4 & 0.5 & 7.2 & 22.6 & 29.5 & 18 & 31.2 \\
\hline & 0.5 & 5.4 & 5.1 & 1 & 28.3 & 25 & 30.0 \\
\hline & 0.6 & 8.5 & 5.8 & 1 & 27.1 & 26.5 & 29.6 \\
\hline & 0.7 & 12.1 & 5.5 & 1 & 25.4 & 26 & 27.4 \\
\hline $\mathrm{LiCl}$ & 0.6 & 1 & 1 & 1 & 30.7 & 24 & 32.9 \\
\hline $\mathrm{NaCl}$ & 0.6 & / & I & 1 & 27.6 & 25 & 29.4 \\
\hline $\mathrm{KCl}$ & 0.6 & 8.5 & 5.8 & 1 & 27.1 & 26.5 & 29.6 \\
\hline KSCN & 0.6 & 7.5 & 5.3 & 1 & 38.7 & 15 & 40.2 \\
\hline $\mathrm{K}_{2} \mathrm{CO}_{3}$ & 0.3 & 3.6 & 6.3 & 1 & 23.5 & 22 & 26.1 \\
\hline
\end{tabular}

Complementary experiments performed in the same salt conditions $(\mathrm{KCl} 0.6 \mathrm{~m})$ by varying the polymer concentration display very similar transition temperatures and enthalpies for both ALG backbone and PNIPAM side-chains (see Figure 11 and Tables S1 and S2 in supporting information). The main differences arise from the viscoelastic behavior that is strongly influenced by the polymer concentration with the level of chain overlapping and entanglements. At low polymer concentration (see $\mathrm{C}_{\mathrm{p}}=1 \mathrm{wt} \%$ in Figure 11), the phase transition of alginates induced by cooling gives rise to a 10 times increase of the viscosity (here $\eta^{*} \sim G^{\prime \prime}$ ) without gelation as already reported for alginate solutions. 

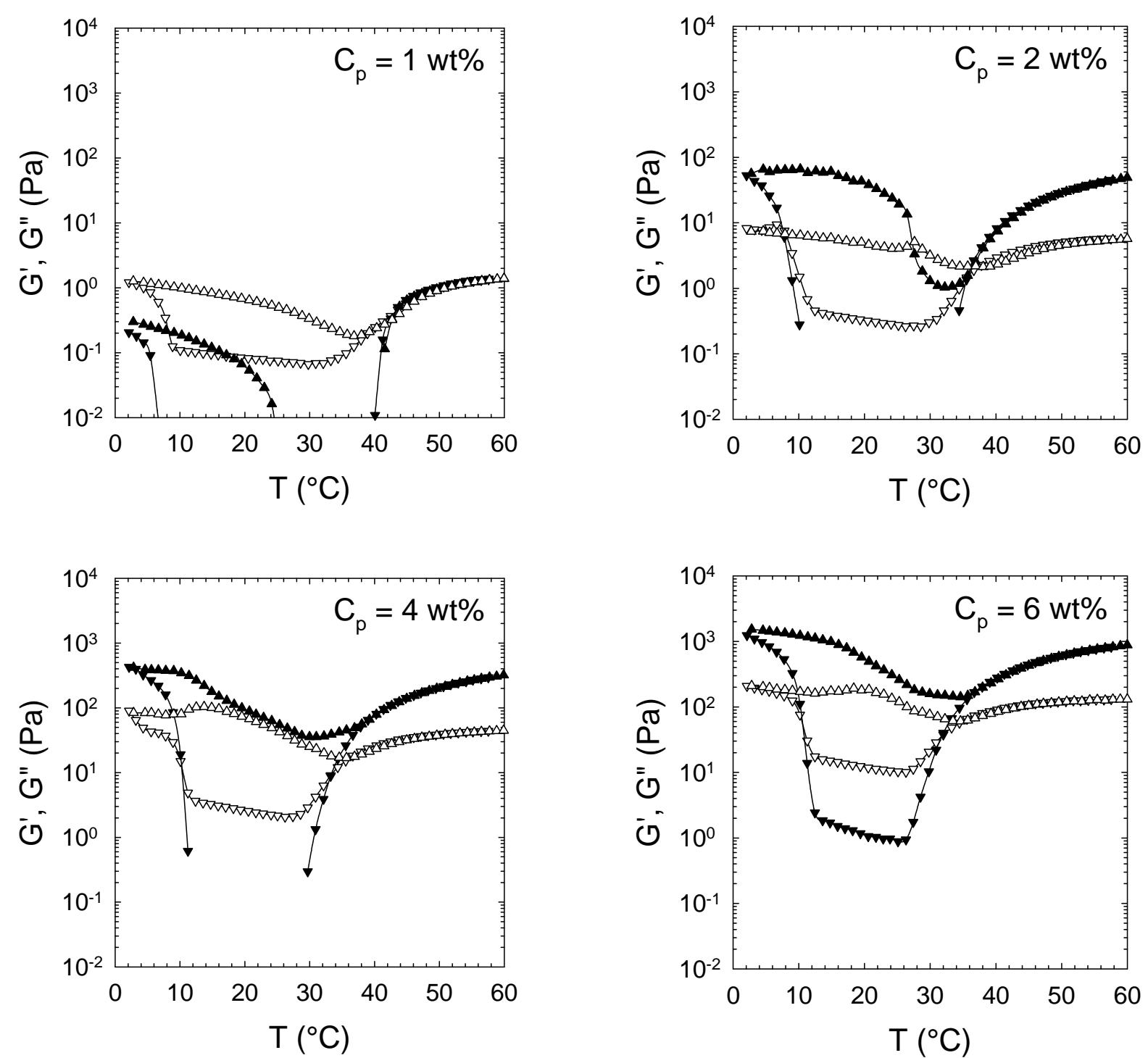

Figure 11. Temperature dependence of dynamic modulus G' (filled symbol) and G" (hollow symbol) of ALG- $g$-PNIPAM aqueous solution $([\mathrm{KCl}]=0.6 \mathrm{~m})$ for different polymer concentrations upon cooling $(\boldsymbol{\nabla} \nabla)$ and heating $(\boldsymbol{\Delta} \triangle)$.

In a different way, the association driven by PNIPAM stickers above $30{ }^{\circ} \mathrm{C}$ reaches the critical conditions of sol/gel transition at about $42^{\circ} \mathrm{C}$ with $\mathrm{G}^{\prime} \cong \mathrm{G}^{\prime}$. For $\mathrm{C}_{\mathrm{p}} \geq 2 \mathrm{wt} \%$, gelation is effective at both low and high temperatures. The main difference is that in the low concentration regime $\left(\mathrm{see} \mathrm{C}_{\mathrm{p}}=2 \mathrm{wt} \%\right.$ in Figure 11 and also $\mathrm{C}_{\mathrm{p}}=3 \mathrm{wt} \%$; see Table $\mathbf{S} 1$ and $\mathbf{S} 2$ in supporting information) there is an intermediate sol state observed during heating taking place between the dissociation of ALG domains and the association of PNIPAM side-chains. Such intermediate state disappears at higher 
concentration $(\mathrm{C} \geq 4 \mathrm{wt} \%)$, leading to a continuous gel state over the whole range of temperature (see also Table S2 in supporting information). The main conclusion is that working in $\mathrm{KCl} 0.6 \mathrm{~m}$, gelation is obtained above a critical concentration $\mathrm{C}_{\mathrm{p}}{ }^{\mathrm{c}}=1-2 \mathrm{wt} \%$ upon cooling and $\mathrm{C}_{\mathrm{p}}{ }^{\mathrm{c}}=1 \mathrm{wt} \%$ upon heating.

\section{Tuning the Gel/Sol/Gel transitions with salts}

\section{Influence of salt concentration}

As salt influences the thermodynamic behavior of alginates and PNIPAM in aqueous solutions, it is an interesting tool for controlling the transition temperatures and therefore the viscoelastic state of the formulations over the whole range of temperatures. Using $\mathrm{KCl}$ as a reference, we can see in Figure

12 that the rheology of grafted alginates can be finely controlled by tuning the salt concentration.
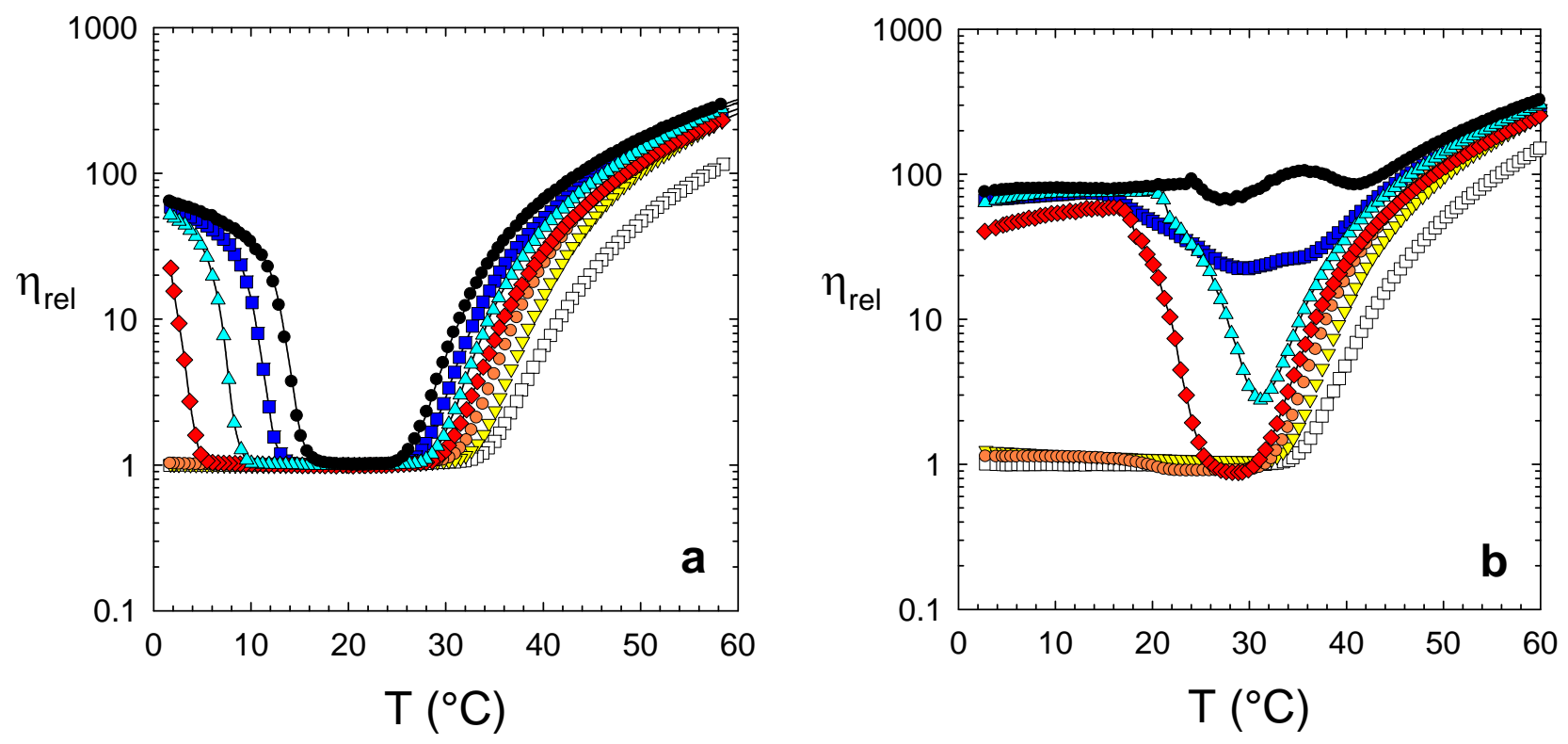

Figure 12. Temperature dependence (a: cooling; $\mathbf{b}$ : heating) of the relative viscosity of ALG- $g$-PNIPAM aqueous solutions $(\mathrm{Cp}=5 \mathrm{wt} \%)$ prepared with $\mathrm{KCl}$ at different molar concentrations: $0(\square) ; 0.2(\nabla) ; 0.3(\bigcirc) ; 0.4(\diamond) ; 0.5(\triangle) ; 0.6(\square)$ and $0.7(\bigcirc)$.

During cooling (Figure 12a), the properties at low temperature are those already described with the alginate sample, i.e. cold gelation for $[\mathrm{KCl}]>0.3 \mathrm{~m}$ and a shift of the transition towards higher temperatures with increasing salt concentration. Concurrently, the transition temperature of PNIPAM is reduced by about $10{ }^{\circ} \mathrm{C}$ by salting out with increasing the $\mathrm{KCl}$ concentration from 0 to $0.6 \mathrm{~m}$ (see 
also Table S3 in supporting information). As $\mathrm{KCl}$ facilitates the two aggregation mechanisms (UCST-type of ALG and LCST-type of PNIPAM), it comes that the temperature range where the solution remains liquid is considerably reduced as the salt concentration increases. If we except the solutions prepared with $[\mathrm{KCl}]<0.4 \mathrm{~m}$, which undergo a single sol/gel transition at high temperature without any strong hysteresis, the solutions prepared at higher salt concentrations display a large set of behaviors during heating due to the overlay of the two aggregation processes (Figure 12b). For instance, with $\mathrm{KCl} 0.4 \mathrm{~m}$, the solution fully recovers a non associating state only in a very narrow temperature range, around $28^{\circ} \mathrm{C}$. At higher salt concentrations, the copolymer chains never fully dissociate and highly viscous or elastic behaviors are observed in the intermediate temperature range for 0.5 and $0.6-0.7 \mathrm{~m}$, respectively (see Figure S7 in supporting information).

\section{Influence of the nature of salt}

While salt concentration is known to impact the phase transition of polymer in aqueous media, the nature of salt can also have a strong influence that can vary according to the mechanism involved. It is well known for instance that the transition temperature of PNIPAM in aqueous solution follows a recurring trend known as the Hoffmeister series that has been established from the ability of the salts to precipitate certain proteins from aqueous solutions. ${ }^{44-46}$ This behavior is more pronounced for anions than cations with typical orders: $\mathrm{CO}_{3}{ }^{2-}>\mathrm{F}^{-}>\mathrm{Cl}^{-}>\mathrm{Br}^{-}$for anions and $\mathrm{K}^{+} \cong \mathrm{Na}^{+}>\mathrm{Li}^{+}$for cations. While the above mentioned anions, referred as kosmotropes, decrease the LCST of PNIPAM (salting-out), some others like $\mathrm{I}^{-}$and $\mathrm{SCN}^{-}$, named chaotropes, are known to have the opposite trend (salting-in). As shown in Figure 13a, the effect of chloride salts on the sol/gel transition related to PNIPAM side-chains is in good agreement with the literature data with a weaker effect for lithium $\left(\mathrm{T}_{\mathrm{g} / \mathrm{s}} \cong 36^{\circ} \mathrm{C}\right)$ compared to sodium and potassium $\left(\mathrm{T}_{\mathrm{g} / \mathrm{s}} \cong 32^{\circ} \mathrm{C}\right)$. The impact of salt is totally different for the association of alginate chains as only potassium ions are able to trigger the aggregation 
process at low temperature. Even if the salt concentration is quite high for high-M alginate, this case is somehow reminiscent with $\kappa$-carrageenan which form gel in aqueous media during cooling much more efficiently and with much higher modulus with $\mathrm{KCl}$ compared to $\mathrm{NaCl}$ or $\mathrm{LiCl}$. One of the explanations given for carrageenan, which could also be applied to the case of alginates, is that $\mathrm{K}^{+}$, being less hydrated than $\mathrm{Na}^{+}$and $\mathrm{Li}^{+}$and having the smallest hydrated radius despite its larger non-hydrated size, interacts more strongly with sulfonate groups forming even ion pairs or bridges between negative charges. ${ }^{47-49}$ While comparable effects were also observed with gellan gum which contains carboxylic groups ${ }^{50-51}$, these effects were not really described in the case of alginates even if some associations promoted by $\mathrm{K}^{+}$were suggested by Rees et al.. ${ }^{52-53}$
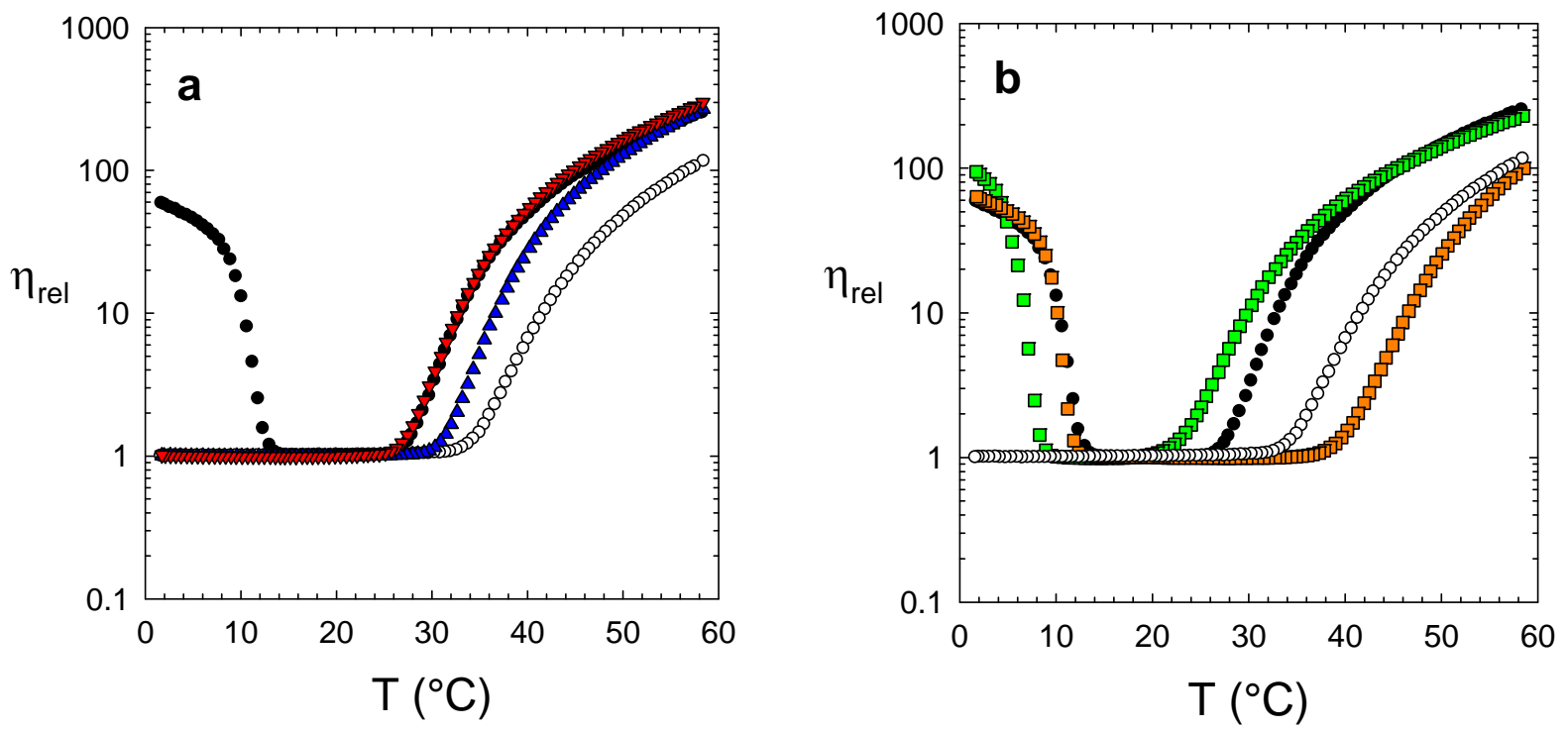

Figure 13. Temperature dependence (during cooling) of the relative viscosity of ALG- $g$-PNIPAM aqueous solution $(\mathrm{Cp}=5 \mathrm{wt} \%)$ in the presence of different (a) chloride salt (salt concentration $=0.6 \mathrm{~m}) \mathrm{LiCl}(\boldsymbol{\Delta}), \mathrm{NaCl}(\boldsymbol{\nabla})$ and $\mathrm{KCl}(\mathbf{O})$; (b) potassium salt $\left(\left[\mathrm{K}^{+}\right]=0.6 \mathrm{~m}\right): \mathrm{K}_{2} \mathrm{CO}_{3}$ $(\square), \mathrm{KSCN}(\square)$ and $\mathrm{KCl}(\mathbf{O}) . \mathrm{H}_{2} \mathrm{O}(\mathrm{O})$ is used as reference. (cooling rate $=2{ }^{\circ} \mathrm{C} \cdot \mathrm{min}^{-1}, \mathrm{f}=1 \mathrm{~Hz}$ ).

In Figure 13b, where the influence of anions was investigated with different potassium salts, we observe an opposite trend with a strong impact of anions on the hot gelation process and a weak influence on the cold one. For a fixed concentration of $\left[\mathrm{K}^{+}\right]=0.6 \mathrm{~m}$, the sol/gel transition of alginate 
chains only decreases from $11.5^{\circ} \mathrm{C}$ for $\mathrm{KCl}$ to $10.2^{\circ} \mathrm{C}$ for $\mathrm{KSCN}$ and $7.9^{\circ} \mathrm{C}$ for $\mathrm{K}_{2} \mathrm{CO}_{3}$ while the hot gelation process spans over $20{ }^{\circ} \mathrm{C}$ : from 28.6 for $\mathrm{K}_{2} \mathrm{CO}_{3}$ and up to $48.6{ }^{\circ} \mathrm{C}$ for $\mathrm{KSCN}$. The relative dissociation temperatures of PNIPAM domains clearly highlighted in Figure $\mathbf{1 3 b}$ as a function of salt are in very good agreement with the literature with a salting-in effect of KSCN which increases the transition temperature with respect to water, and salting-out with $\mathrm{KCl}$ and $\mathrm{K}_{2} \mathrm{CO}_{3}$, the later being much more efficient in decreasing the $\mathrm{LCST}^{46}$ From the alginate side, there is almost no difference between $\mathrm{KCl}$ and $\mathrm{KSCN} 0.6 \mathrm{~m}$ but lower transition temperatures are obtained for $\mathrm{K}_{2} \mathrm{CO}_{3} 0.3 \mathrm{~m}$, as well as for $\mathrm{K}_{2} \mathrm{SO}_{4} 0.3 \mathrm{~m}$ and $\mathrm{K}_{3} \mathrm{PO} 40.2 \mathrm{~m}$ (results not shown here), meaning that multivalent anions interfere negatively on the gelation process of alginates.

\section{General discussion}

Using the macromolecular data obtained from SEC for ALG at relatively high ionic strength $\left([\eta]=385 \mathrm{~mL} / \mathrm{g}\right.$ in $\left.\left[\mathrm{NaNO}_{3}\right]=0.2 \mathrm{~m}\right)$, the overlap concentration of alginate chains can be roughly estimated at $\mathrm{C}^{*} \cong 1 /[\eta]=2.5 \mathrm{~g} / \mathrm{L} \cong 0.25 \mathrm{wt} \%$. Above this concentration, that separates the dilute and the semi-dilute unentangled regimes, the polymer chains start to overlap and increase their contact up to the concentration $\mathrm{C}_{\mathrm{e}}$ where entanglements dominate the viscoelastic properties. For neutral polymer or polyelectrolyte solutions studied at high salt concentration, the ratio between these two concentrations is $C_{e} / C^{*} \cong 5-10$ but other criterions can be used to define $C^{*}$ and $C_{e}$ as the concentrations where the viscosity of the polymer solutions become equal to $\eta^{* \cong 2} \eta_{s}$ and $\eta_{e} \cong 50 \eta_{s}$ respectively, with $\eta_{s}$ the viscosity of the solvent. ${ }^{54-55}$ Moreover, in the semi-dilute unentangled regime $\left(C^{*}<C<C_{e}\right)$, the variation of the specific viscosity $\left(\eta_{s p}=\left(\eta-\eta_{s}\right) / \eta_{s}\right)$ versus the concentration follows a power law $\eta_{s p} \propto C^{\alpha}$ with moderate scaling coefficients $(\alpha=2$ or $5 / 4$ in $\Theta$-conditions or good solvent, respectively), whereas in the semi-dilute entangled regime $\left(C>C_{e}\right)$ these coefficients are much larger $(\alpha=14 / 3$ or $15 / 4$ in $\Theta$-conditions or good solvent, respectively). As shown in Figure 
14, the $\log -\log$ plots of $\eta_{s p}$ versus the concentration obtained for both ALG and ALG- $g$-PNIPAM in $\mathrm{KCl} 0.6 \mathrm{~m}$ at $20{ }^{\circ} \mathrm{C}$ upon cooling, i.e. in absence of specific associations, gives relatively high exponents $(\alpha=3.5-3.8)$ in agreement with theoretical values expected for entangled macromolecules in good solvent. These scaling relations are determined for $\mathrm{C}_{\mathrm{p}} \geq 2 \mathrm{wt} \%$ as the experimental values of $\eta_{s p}$ obtained at $1 \mathrm{wt} \%$ depart from the above relations and the viscosities are clearly below the criterion $\eta_{e} \cong 50 \eta_{s}$. If the viscosity of ALG and ALG- $g$-PNIPAM solutions follow the same trend, the main difference between the two samples originates from the concentration of ALG backbone that mainly contributes to entanglements and which is $40 \mathrm{wt} \%$ lower in the ALG- $g$-PNIPAM compared to ALG when prepared at the same total concentration. From this first analysis we can conclude that the entanglement regime is reached for concentrations above $1 \mathrm{wt} \%$ and this is typically the concentration regime where a true gel behavior with elastic properties was observed for alginates solutions.

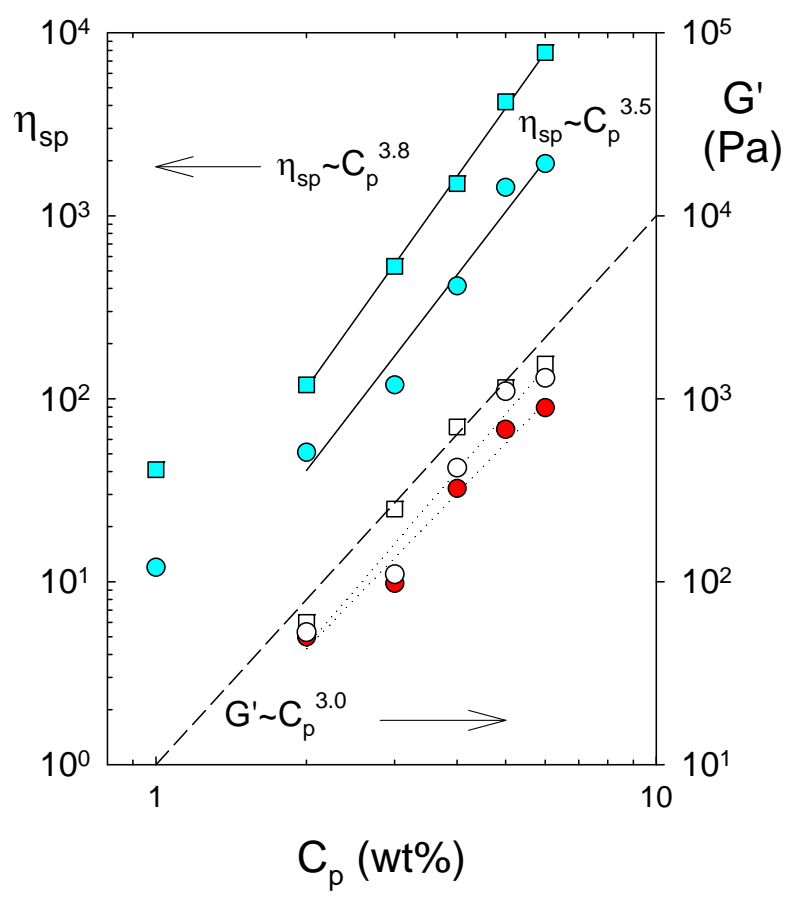

Figure 14

Concentration dependence of the specific viscosity $\left(\eta_{s p}\right)$ for solutions prepared in $\mathrm{KCl} 0.6 \mathrm{~m}$ at $20^{\circ} \mathrm{C}$ upon cooling. ( $\square$ ALG and $\bigcirc$ ALG-g-PNIPAM)

Concentration dependence of the elastic modulus $\left(\mathrm{G}^{\prime}\right)$ of alginate gels prepared in $\mathrm{KCl} 0.6 \mathrm{~m}$ : $\square \mathrm{ALG}$ at $\mathrm{T}=2{ }^{\circ} \mathrm{C}$

O ALG- $g$-PNIPAM at $\mathrm{T}=2{ }^{\circ} \mathrm{C}$ ALG- $g$-PNIPAM at $\mathrm{T}=60{ }^{\circ} \mathrm{C}$

For entangled networks made up of linear chains with temporary cross-links, the elastic modulus $(G)$ has contributions from both cross-links $\left(G_{c}\right)$ and entanglements $\left(G_{e}\right)$ at times shorter than the lifetime 
of a cross-link $(\tau)$ and longer than the Rouse time of an entanglement strand $\left(\tau_{e}\right)$. This is typically the situation for ALG and ALG-g-PNIPAM solutions as the physical interactions taking place at low $\left(2{ }^{\circ} \mathrm{C}\right)$ and high $\left(60^{\circ} \mathrm{C}\right)$ temperatures are "strong" enough, i.e. the dissociation rate constant is slow at the time scale of the experiment $(t<\tau)$. If we plot the elastic modulus versus the polymer concentration (Figure 14), all the gels prepared by heating or cooling exhibit very similar concentration dependence with a scaling exponent $\left(G \propto C_{p}^{\beta}\right)$ close to 3. By comparison, similar values were already reported in previous works for cold gelation of ALG sample in $\mathrm{K}_{2} \mathrm{CO}_{3} 0.3 \mathrm{~m}^{35}$ $(\beta=2.6)$ as well as for nano-hybrid networks where adsorbing silica nano-particles are embedded into a chemical hydrogel of poly $(N, N \text {-dimethylacrylamide })^{56} \quad(\beta=2.6)$. With reference to the non-associated state, where only the entanglements contribute to the elastic modulus as $G_{e} \propto C_{p}^{9 / 4}$ (assuming good solvent conditions), the strong dependence of the modulus with the concentration in the gel states, $G \propto C_{p}^{9 / 4} C_{p}^{3 / 4}$, can be considered as a signature of the coupling between physical cross-links and entanglements. If the modulus of the gels formed at low and high temperature in the presence of $0.6 \mathrm{~m} \mathrm{KCl}$ are very close and have a similar concentration dependence, it should be known that this similarity strongly rely on the composition of the copolymer and that the mechanisms of association are of very different natures.

At high temperature, the general picture that can be given for this graft copolymer is that of the formation of a micellar network where PNIPAM chains self-assemble into micro-domains physically cross-linking the water-soluble matrix; alginate in the present case. The nano-metric aggregates of PNIPAM, that retain only a small fraction of water (30 wt $\%$ ), have a very low dynamics and these physical cross-links have a very long lifetime which make these physical gels very stable with time. While PNIPAM is well-known as a temperature-responsive polymer, it is also very sensitive to many molecules that can be added into the solution and inorganic salts in particular. The effect of salts on 
the LCST of PNIPAM has been widely studied and the key points are that the solubility of PNIPAM chains is mainly affected by anions and that the impact of these anions depends strongly if they are kosmotropic or chaotropic. ${ }^{46,57}$ In the first case, highly hydrated anions, like $\mathrm{SO}_{4}{ }^{2-}, \mathrm{CO}_{3}{ }^{2-}, \mathrm{F}^{-} \ldots$, decrease the solubility of PNIPAM by polarizing the water molecules which form hydrogen bonds around the amide group of NIPAM units and by increasing the surface tension at the water/hydrophobic interface (salting-out). Less hydrated anions also increase the surface tension but they can also bind to macromolecules, like $\mathrm{SCN}^{-}$, giving rise to salting-in. ${ }^{46}$ From a general point of view we can see that the solubility of PNIPAM is a complex mechanism that involves very different interactions like hydrogen bonds, hydrophobic and even ion binding.

At low temperature, the mechanism of gelation of high-M alginates has hardly been studied but it can be emphasized from our series of experiments that neither the hydrophobic interactions nor the hydrogen bonds are the key interactions of the association process. The gelling mechanism induced at low temperature by the association between mannuronic sequences is mainly induced by the cations and in the series of alkali metals that has been tested $\mathrm{Li}^{+}, \mathrm{Na}^{+}, \mathrm{K}^{+}$, only potassium is able to drive the association process. We can also mention that larger alkali metals like $\mathrm{Cs}^{+}$(not shown here) behave similarly to potassium. The hypothesis is then that chaotropic cations, which are less hydrated than kosmotropic ones $\left(\mathrm{Li}^{+}\right.$and $\left.\mathrm{Na}^{+}\right)$, can more strongly interact with carboxylic groups of mannuronic units by forming ions pairs or inter-chain bridges as it was reported for the salt-induced gelation of carrageenans. $^{47-49}$

Although the exact mechanism of cold gelation of high-M alginates remains an open question, the main result of this paper is that a copolymer with schizophrenic thermo-responsive properties, coupling UCST and LCST behaviors, can be readily obtained by grafting PNIPAM chains on a high-M alginate backbone. Since the association process of alginate and PNIPAM are strongly 
modified, respectively by cations or by anions, this means that the choice of salt is critical and that one or the two mechanisms can be selectively regulated by choosing the appropriate salt. This selective activation/deactivation of the self-assemblies is exemplified in Table 4 for three different temperatures, 5,32 and $38{ }^{\circ} \mathrm{C}$, on the basis of our experimental data and their extrapolation to other salts.

Table 4. Different states of ALG- $g$-PNIPAM solutions obtained during cooling in the presence of various monovalent salts $(0.6 \mathrm{~m})$ at three given temperatures: "- -": sol state; "-_": gel state.

\begin{tabular}{|c|c|c|c|c|c|c|}
\hline & No salt & $\mathrm{NaCl}$ & $\mathrm{KCl}$ & $\mathrm{KSCN}$ & $\mathrm{NaSCN}^{\mathrm{a}}$ & $\mathrm{KI}^{\mathrm{a}}$ \\
\hline $5{ }^{\circ} \mathrm{C}$ & -- & -- & - & - & -- & - \\
\hline $32^{\circ} \mathrm{C}$ & -- & - & - & -- & -- & -- \\
\hline $38^{\circ} \mathrm{C}$ & - & - & - & -- & -- & - \\
\hline
\end{tabular}

\section{CONCLUSIONS}

The aim of this work was to take advantage of the specific behavior of high-M alginates, which show reversible gelation upon cooling in certain salt conditions, to design an original copolymer with schizophrenic gelling properties. This has been demonstrated by grafting PNIPAM side-chains onto the alginate backbone. Based on this grafted architecture, we have shown that the two opposite association processes, driven by the LCST of PNIPAM side-chains and the UCST of mannuronic sequences, can be triggered independently from one another without interference between the two. Indeed, sine the aggregation of PNIPAM which couples the hydrophobic interactions and the hydrogen bonds can be reinforced by anions, and the association of mannuronic sequences is clearly controlled by cation binding, the schizophrenic behavior of the graft copolymer can then be selectively controlled by the choice of the salt. In addition, since the association/dissociation behavior of high $\mathrm{M}$ alginates exhibits a high hysteresis, greater than $20{ }^{\circ} \mathrm{C}$, their derivatives offer a great versatility not only in terms of salt (nature and concentration) but also in terms of preparation since 
different states, sol or gel, can be obtained at the same temperature. While the exact mechanism of the aggregation process of high-M alginates remains under investigation, this polysaccharide forms a very interesting platform for developing responsive systems for biomedical applications. Such work is actually developed in our group in order to investigate how the nature, the size and/or the number of LCST side-chains can modify the viscoelastic properties under small and large deformations.

\section{ASSOCIATED CONTENT}

\section{Supporting information}

Detailed synthesis of ALG-g-PNIPAM, sol/gel transition of ALG as a function of polymer concentration and added SDS or urea, viscoelastic and calorimetric analysis of ALG-g-PNIPAM as a function of $\mathrm{KCl}$ concentration, transition temperatures of ALG-g-PNIPAM solutions for different salts, salt concentrations and polymer concentrations.

\section{ACKNOWLEDGEMENTS}

The authors want to acknowledge Brothier Laboratories (Fontevraud-l'Abbaye, France) with Philippe Maingault, Florence Brunel and Stéphane Lack for supporting the initial work on alginates. The authors also thank Mohamed Hanafi for his contribution on performing SEC and DSC experiments.

\section{REFERENCES}

1. Haug, A.; Larsen, B.; Smidsrod, O., A study on the constitution of alginic acid by partial acid hydrolysis. Acta Chem. Scand. 1966, 20, 271-277.

2. Haug, A.; Larsen, B.; Smidsrod, O., Studies on sequence of uronic acid residues in alginic acid. Acta Chem. Scand. 1967, 21, 691-704. 
3. Draget, K. I., In Handbook of Hydrocolloids, Phillips, G. O.; Williams, P. A., Eds. CRC Press: Boca Raton, FL, 2000; pp 379-395.

4. Andresen, I.-L.; Skipnes, O.; Smidsrød, O.; Østgaard, K.; Hemmer, P. C., Some biological functions of matrix components in benthic algae in relation to their chemistry and the composition of seawater. ACS Symposium Series 48; American Chemical Society: Washington, DC, 1977; pp $361-381$

5. Grant, G. T.; Morris, E. R.; Rees, D. A.; Smith, P. J. C.; Thom, D., Interactions between polysaccharides and divalent cations - egg-box model. FEBS Lett. 1973, 32, 195-198.

6. Brownlee, L. A.; Seal, C. J.; Wilcox, M.; Dettmar, P. W.; Pearson, J. P., Applications of Alginates in Food. In Alginates: Biology and Applications, Rehm, B. H. A., Ed. 2009; Vol. 13, pp 211-228.

7. Paul, W.; Sharma, C. P., Trends Biomater. Artif. Organs 2004, 18, 18-23.

8. Qin, Y., Alginate fibres: an overview of the production processes and applications in wound management. Polym. Int. 2008, 57, 171-180.

9. Cook, W., Alginate dental impression materials - chemistry, structure, and properties. J. Biomed. Mater. Res. A 1986, 20, 1-24.

10. Wang, L.; Shelton, R. M.; Cooper, P. R.; Lawson, M.; Triffitt, J. T.; Barralet, J. E., Evaluation of sodium alginate for bone marrow cell tissue engineering. Biomaterials 2003, 24, 3475-3481.

11. Wong, M., In Biopolymer Methods in Tissue Engineering, Hollander, A. P.; Hatton, P. V., Eds. Humana Press Inc.: Totowa, NJ, 2004; pp 77-86.

12. Ma, P. X., In Scaffolding in Tissue Engineering, Ma, P. X.; Elisseeff, J., Eds. CRC Press: Boca Raton, FL, 2006; pp 13-26.

13. Augst, A. D.; Kong, H. J.; Mooney, D. J., Alginate hydrogels as biomaterials. Macromol. Biosci. 2006, 6, 623-633.

14. Sachan, N. K.; Pushkar, S.; Jha, A.; Bhattcharya, A., Sodium alginate: the wonder polymer for controlled drug delivery. J. Pharm. Res. 2009, 2, 1191-1199.

15. Liu, M.; Zeng, X.; Ma, C.; Yi, H.; Ali, Z.; Mou, X. B.; Li, S.; Deng, Y.; He, N. Y., Injectable hydrogels for cartilage and bone tissue engineering. Bone Res. 2017, 5, 20.

16. Jing, J.; Alaimo, D.; De Vlieghere, E.; Jerome, C.; De Wever, O.; De Geest, B. G.; Auzely-Velty, R., Tunable self-assembled nanogels composed of well-defined thermoresponsive hyaluronic acid-polymer conjugates. J. Mater. Chem. B 2013, 1, 3883-3887.

17. Ruel-Gariepy, E.; Leroux, J. C., In situ-forming hydrogels - review of temperature-sensitive 
systems. Eur. J. Pharm. Biopharm. 2004, 58, 409-426.

18. Kharkar, P. M.; Kiick, K. L.; Kloxin, A. M., Designing degradable hydrogels for orthogonal control of cell microenvironments. Chem. Soc. Rev. 2013, 42, 7335-7372.

19. Klouda, L.; Mikos, A. G., Thermoresponsive hydrogels in biomedical applications. Eur. J. Pharm. Biopharm. 2008, 68, 34-45.

20. Kumashiro, Y.; Huh, K. M.; Ooya, T.; Yui, N., Modulatory factors on temperature-synchronized degradation of dextran grafted with thermoresponsive polymers and their hydrogels.

Biomacromolecules 2001, 2, 874-879.

21. Karakasyan, C.; Lack, S.; Brunel, F.; Maingault, P.; Hourdet, D., Synthesis and rheological properties of responsive thickeners based on polysaccharide architectures. Biomacromolecules 2008, 9, 2419-2429.

22. White, J. C.; Saffer, E. M.; Bhatia, S. R., Alginate/PEO-PPO-PEO Composite Hydrogels with Thermally-Active Plasticity. Biomacromolecules 2013, 14, 4456-4464.

23. Kumar, J. N.; Pang, V. Y. T.; Aik, S. X. L., Calcium triggered self-assembly of alginate-graft-POEGMA via RAFT for the encapsulation of lipophillic actives. J. Mater. Chem. B 2017.

24. Swamy, B. Y.; Chang, J. H.; Ahn, H.; Lee, W. K.; Chung, I., Thermoresponsive N-vinyl caprolactam grafted sodium alginate hydrogel beads for the controlled release of an anticancer drug. Cellulose 2013, 20, 1261-1273.

25. Tan, R. W.; She, Z. D.; Wang, M. B.; Fang, Z.; Liu, Y. S.; Feng, Q. L., Thermo-sensitive alginate-based injectable hydrogel for tissue engineering. Carbohydr. Polym. 2012, 87, 1515-1521. 26. Cheaburu, C. N.; Ciocoiu, O. N.; Staikos, G.; Vasile, C., Thermoresponsive sodium alginate-g-poly(N-isopropylacrylamide) copolymers III. Solution properties. J. Appl. Polym. Sci. 2013, $127,3340-3348$.

27. Lencina, M. M. S.; Iatridi, Z.; Villar, M. A.; Tsitsilianis, C., Thermoresponsive hydrogels from alginate-based graft copolymers. Eur. Polym. J. 2014, 61, 33-44.

28. Hourdet, D.; Lalloret, F.; Audebert, R., Reversible thermothickening of aqueous polymer-solutions. Polymer 1994, 35, 2624-2630.

29. Durand, A.; Hourdet, D., Synthesis and thermoassociative properties in aqueous solution of graft copolymers containing poly(N-isopropylacrylamide) side chains. Polymer 1999, 40, 4941-4951. 30. Durand, A.; Hervé, M.; Hourdet, D., Thermogelation in Aqueous Polymer Solutions. In 
Stimuli-Responsive Water Soluble and Amphiphilic Polymers, American Chemical Society: 2000; Vol. 780, pp 181-207.

31. Lalloret, F.; Maroy, P.; Hourdet, D.; Audebert, R., Reversible thermoassociation of water-soluble polymers. Revue De L Institut Francais Du Petrole 1997, 52, 117-128.

32. Gupta, N. R.; Torris A. T, A.; Wadgaonkar, P. P.; Rajamohanan, P. R.; Ducouret, G.; Hourdet, D.; Creton, C.; Badiger, M. V., Synthesis and characterization of PEPO grafted carboxymethyl guar and carboxymethyl tamarind as new thermo-associating polymers. Carbohydr. Polym. 2015, 117, $331-338$.

33. Vasile, C.; Nita, L. E., Novel multi-stimuli responsive sodium alginate-graftedpoly(N-isopropylacrylamide) copolymers: II. Dilute solution properties. Carbohydr. Polym. 2011, 86, 77-84.

34. Guo, H.; Brûlet, A.; Rajamohanan, P. R.; Marcellan, A.; Sanson, N.; Hourdet, D., Influence of topology of LCST-based graft copolymers on responsive assembling in aqueous media. Polymer 2015, $60,164-175$.

35. Karakasyan, C.; Legros, M.; Lack, S.; Brunel, F.; Maingault, P.; Ducouret, G.; Hourdet, D., Cold Gelation of Alginates Induced by Monovalent Cations. Biomacromolecules 2010, 11, 2966-2975.

36. Donati, I.; Paoletti, S., Material Properties of Alginates. In Alginates: Biology and Applications, Rehm, B. H. A., Ed. Springer Berlin Heidelberg: Berlin, Heidelberg, 2009; pp 1-53.

37. Winter, H. H.; Chambon, F., Analysis of Linear Viscoelasticity of a Crosslinking Polymer at the Gel Point. J. Rheol. 1986, 30, 367-382.

38. Portehault, D.; Petit, L.; Pantoustier, N.; Ducouret, G.; Lafuma, F.; Hourdet, D., Hybrid thickeners in aqueous media. Colloids Surf., A 2006, 278, 26-32.

39. Mortensen, K.; Brown, W.; Jorgensen, E., Phase-behavior of poly(propylene oxide) poly(ethylene oxide) poly(propylene oxide) triblock copolymer melt and aqueous-solutions. Macromolecules 1994, 27, 5654-5666.

40. Hourdet, D.; L'Alloret, F.; Durand, A.; Lafuma, F.; Audebert, R.; Cotton, J. P., Small-angle neutron scattering study of microphase separation in thermoassociative copolymers. Macromolecules 1998, 31, 5323-5335.

41. Hourdet, D.; Gadgil, J.; Podhajecka, K.; Badiger, M. V.; Brulet, A.; Wadgaonkar, P. P., Thermoreversible behavior of associating polymer solutions: Thermothinning versus thermothickening. Macromolecules 2005, 38, 8512-8521. 
42. Badiger, M. V.; Rajamohanan, P. R.; Kulkarni, M. G.; Ganapathy, S.; Mashelkar, R. A., Proton MASS-NMR: a new tool to study thermoreversible transition in hydrogels. Macromolecules 1991, 24, 106-111.

43. Rusu, M.; Wohlrab, S.; Kuckling, D.; Möhwald, H.; Schönhoff, M., Coil-to-Globule Transition of PNIPAM Graft Copolymers with Charged Side Chains: A 1H and 2H NMR and Spin Relaxation Study. Macromolecules 2006, 39, 7358-7363.

44. Kunz, W.; Henle, J.; Ninham, B. W., 'Zur Lehre von der Wirkung der Salze' (about the science of the effect of salts): Franz Hofmeister's historical papers. Curr. Opin. Colloid Interface Sci. 2004, 9 , 19-37.

45. Schild, H. G.; Tirrell, D. A., Microcalorimetric detection of lower critical solution temperatures in aqueous polymer solutions. J. Phys. Chem. 1990, 94, 4352-4356.

46. Zhang, Y.; Furyk, S.; Bergbreiter, D. E.; Cremer, P. S., Specific Ion Effects on the Water Solubility of Macromolecules: PNIPAM and the Hofmeister Series. J. Am. Chem. Soc. 2005, 127, 14505-14510.

47. Norton, I. T.; Morris, E. R.; Rees, D. A., Lyotropic effects of simple anions on the conformation and interactions of kappa-carrageenan. Carbohydr. Res. 1984, 134, 89-101.

48. Watase, M.; Nishinari, K., The effect of monovalent cations and anions on the rheological properties of kappa-carrageenan gels. J. Texture Stud. 1988, 19, 259-273.

49. Rochas, C.; Rinaudo, M., Activity coefficients of counterions and conformation in kappa-carrageenan systems. Biopolymers 1980, 19, 1675-1687.

50. Miyoshi, E.; Nishinari, K., Rheological and thermal properties near the sol-gel transition of gellan gum aqueous solutions. In Physical Chemistry and Industrial Application of Gellan Gum, Nishinari, K., Ed. Springer Berlin Heidelberg: Berlin, Heidelberg, 1999; pp 68-82.

51. Ogawa, E.; Matsuzawa, H.; Iwahashi, M., Conformational transition of gellan gum of sodium, lithium, and potassium types in aqueous solutions. Food Hydrocoll. 2002, 16, 1-9.

52. Thom, D.; Grant, G. T.; Morris, E. R.; Rees, D. A., Characterisation of cation binding and gelation of polyuronates by circular dichroism. Carbohydr. Res. 1982, 100, $29-42$.

53. Seale, R.; Morris, E. R.; Rees, D. A., Interactions of alginates with univalent cations. Carbohydr. Res. 1982, 110, 101-112.

54. Dobrynin, A. V.; Colby, R. H.; Rubinstein, M., Scaling theory of polyelectrolyte solutions. Macromolecules 1995, 28, 1859-1871. 
55. Colby, R. H., Structure and linear viscoelasticity of flexible polymer solutions: comparison of polyelectrolyte and neutral polymer solutions. Rheol. Acta 2010, 49, 425-442.

56. Carlsson, L.; Rose, S.; Hourdet, D.; Marcellan, A., Nano-hybrid self-crosslinked PDMA/silica hydrogels. Soft Matter 2010, 6, 3619-3631.

57. Freitag, R.; Garret-Flaudy, F., Salt Effects on the Thermoprecipitation of

Poly-(N-isopropylacrylamide) Oligomers from Aqueous Solution. Langmuir 2002, 18, 3434-3440. 